\title{
Articles
}

The Person and the Challenges

Volume 3 (2013) Number 1, p. 7-42

Zbigniew Waleszczuk

Catholic University of Eichstaett-Ingolstadt, Germany

\section{Der Kategorische Imperativ als Grundstein der Menschenwürde und Form der Offenbarung Gottes bei Immanuel Kant und Karol Wojtyla}

\section{The Categorical Imperative as Cornerstone for Human Dignity and Form of Revelation of God in the Work of Immanuel Kant and Karol Wojtyla}

\begin{abstract}
The aim of this analysis is to show the categorical imperative as the cornerstone of human dignity and form of revelation of God in the work of Immanuel Kant and Karol Wojtyla. The suspicious and distant attitude of Christian philosophers, as well as the Catholic Church compared to Kant has a long history. To this day there are only a few researches that analyse from this point of view (Kantian influences) the philosophical thinking of Karol Wojtyla. Though Kant identified the question of God as the cardinal question of our abstract rationality, he believed in God and future life, even in his lifetime he was underestimated, misunderstood and treated with hostility. The experience of duty is"ratio conoscendi" of freedom in Kant and Wojtyla. For the two thinkers the question of freedom is the basic category of there philosophies. Through which authority moral law challenges the human being? Kant and Wojtyla, both philosophers comprehend the highest authority as divine power which formulated the moral law before man. The "holy lawmaker" - God - reveals himself in the human act.
\end{abstract}

\section{Keywords}

Karol Wojtyła, a person, freedom, God, duty, the categorical imperative, Immanuel Kant. 
Wenn in deinem Verhalten eine Person Objekt deines Handelns ist, vergiss niemals, dass du sie nicht bloß als Mittel, als Werkzeug behandeln darfst, sondern sei dir bewusst, dass sie ihr eigenes Ziel hat oder wenigstens haben sollte.

K. Wojtyla, Liebe und Verantwortung ${ }^{1}$.

Der categor. Imper. u. das darauf gegründete Erkentnis aller Menschen Pflichten als Göttlicher Gebote ist der practische Beweis vom Daseyn Gottes².

Die moderne Kultur scheint die transzendente Auffassung des Menschen immer mehr zu bestreiten. Es verbreiten sich Vereinsamung und Nihilismus, Verzweiflung, Alienation ${ }^{3}$, und Orientierungslosigkeit ${ }^{4}$. Diese dominierenden Folgen der im Grunde atheistischen und materialistischen Perspektive, sind die Hauptursache der gegenwärtigen Krisen, die nicht nur unsere Finanzen und die Wirtschaft ruinieren, sondern auch im kulturellen Bereich vernichtende Folgen haben 5 . Der weit verbreitete Nihilismus, vor allem in unserem westlichen Kulturkreis, kann uns deshalb nicht weiter helfen. Im Gegenteil, solche selbstzerstörerischen Tendenzen, die unter anderem auf die Frage nach Gott und Seiner Offenbarung keine Antworten formulieren können sie als irrelevant brandmarken, schwächen die mögliche ethische Diskussion jeder stabilen Grundlage ${ }^{6}$. Wie Karl Lehmann feststellt: „Es ist Zeit an Gott

1 K. Wojtyła, Liebe und Verantwortung, S. 25. K. Wojtyła, in: Nsissing (Hg.), Wer ist der Mensch?, S. XVIII.

2 I. Kant, AA 21,74; Siehe: A. Winter, „Es ist ein Gott denn es ist ein categ. Imperativ“. Versteckte Ansätze zur Gottesfrage in der Kritik der praktischen Vernunft, in: N. Fischer, Die Gottesfrage in der Philosophie Immanuels Kants, Herder 2010, S. 108.

3 Siehe K. Wojtylas Äußerungen zur marxistischen Theorie der Gesellschaft. Vgl. Z. Waleszczuk, Globalizacja solidarnosci, Wroclaw 2007, S. 263.

4 Atheismus, Relativismus, Nihilismus und Ökonomismus führen nicht nur zu bankrott des Kapitalismus, sind auch keine Überwindung des Kommunismus. Vgl. W. Ockenfels, Was kommt nach dem Kapitalismus?, Augsburg 2011.

5 Als Beleg für diese ernüchternde These können wir z.B. einen Prestigeverlag erwähnen: Oxford University Press, der ein Buch unter dem vielsagenden Titel herausgegeben hat: David Benatar, Better never to have been: the harm of coming into existence, Oxford 2006.

6 Es verwundert deshalb auch nicht, dass z.B. einige Professoren der Biologie in Oxford sich für das Recht der Tötung von behinderten Neugeborenen aussprechen, was uns die berechtigte Frage stellen lässt, ob solche Aussagen sich noch von der Ideologie des Faschismus unterscheiden, bei der der Mensch als lebenswert oder -unwert selektiert wurde. Siehe: S. Rehder, Bioethiker werben für Kindsmord, „Die Tagespost“, Nr. 28 (6.03.2012), S. 2. 
zu denken" "7. In den dominierenden Massenmedien wird der Mensch immer öfter nicht mehr wie ein Subjekt (Person) behandelt, sondern zunehmend mit einem Tier oder einer Sache gleichgesetzt ${ }^{8}$. Walter Kasper weist in diesem Zusammenhang auf die Philosophie Immanuel Kants hin, die unseren Untersuchungen um die absolute Würde des Menschen und der „Spuren Gottes“ in der Welt eine sichere Grundlage bietet. Der Kardinal schreibt in seinem neuen Buch „Barmherzigkeit. Grundbegriff des Evangeliums - Schlüssel christlichen Lebens“, dazu: „Im Sinne Kants kann man von einem Postulat sprechen, das besagt: wenn absolute Würde des Menschen sein soll, dann nur, wenn Gott ist und wenn ein Gott des Erbarmens und der Gnade ist" ${ }^{\text {"9 }}$. Die Gottesfrage bezeichnet Kant als eine der ersten »Cardinalsätze unserer reinen Vernunft $\ll^{10}$,»es ist ein Gott, es ist ein künftiges Leben $\aleph^{11}$. Die misstrauische und distanzierte Einstellung gegenüber Kant seitens der christlichen Philosophen, sowie der offiziellen Kirche hat eine lange Geschichte. Kant wurde bereits zu seinen Lebzeiten unterschätzt, missverstanden und angefeindet ${ }^{12}$. Im Jahre 1827 wurden seine Schriften von Papst Leo XII. auf den Index librorum prohibitorum gesetzt. Noch 140 Jahre später, im Jahr 1963, während des II. Vatikanischen Konzils musste Aloisius Winter um die offizielle Erlaubnis des Vatikans, die Bücher Kants lesen zu dürfen, bitten. Es ist deshalb nicht verwunderlich, dass viele Interpreten (vor allem katholischerseits) keinen ausreichenden Kontakt mit den Originalschriften hatten. Bis heute erwähnen manche Autoren Kant lediglich nebenbei, und unterstellen ihm eine falsch verstandene Position. Noch im Jahre 2004 behauptet Giovanni Sala SJ, dass

7 K. Lehmann, Es ist Zeit an Gott zu denken, Herder 2000.

8 Vgl. M. Białoszewski, Atak zombie, „Fronda” 53 (2009), S. 209.

9 W. Kasper, Barmherzigkeit. Grundbegriff des Evangeliums - Schlüssel christlichen Lebens, Herder 2012, S. 14.

${ }^{10}$ I. Kant, $K r V$ B $769 f$.

${ }^{11}$ Vgl. z. B. Kant B 827 und 831. Zit. nach. N. Fischer, Die Gottesfrage in der Philosophie Immanuels Kants, Herder 2010, S. IX. „Kant betreibt Philosophie in Sokratischem Geiste (B XXXI) - und ist (ähnlich wie Augustinus) angeregt von Grundfragen, die sich ihm auch aus dem biblischen Glauben aufgedrängt haben. Das wir es nach Kant »in einem Kanon der reinen Vernunft nur mit zwei Fragen zu thun« haben, »die das praktische Interesse der reinen Vernunft angehen, und in Ansehung derer ein Kanon ihres Gebrauchs moglich sein mus, namlich: ist ein Gott? ist ein kunftiges Leben?«, last sich überdies der Sache nach als eine wenigstens indirekte Referenz auf Augustinus verstehen“. N. Fischer (Hg.), Kants Grundlegung einer reinen Metaphysik, Meiner Verlag Hamburg 2010, S. 2.

${ }_{12}$ A. Winter, Der andere Kant. Zur philosophischen Theologie Immanuel Kants, HildesheimZürich-New York 2000. 
Kant eine absolute Autonomie der Freiheit auslegt ${ }^{13}$. Wie Norbert Fischer dazu schreibt, versteht Kant Autonomie „nicht als die Selbstbestimmung einzelner Subjekte, sondern die Selbstgesetzgebung der Vernunft, die zugleich als göttliches Gebot zu verstehen ist" ${ }^{\text {"14 }}$. Die Absicht unserer Untersuchung ist es, den Kategorischen Imperativ als Grundstein der Menschenwürde und Form der Offenbarung Gottes bei Immanuel Kant und Karol Wojtyla darzustellen. Die Tatsache, dass Kants Auffassung der menschlichen Person als Zweck an sich eine Grundlage für die anthropologischen Aussagen des II. Vatikanischen Konzils, besonders Gaudium et spes, bildete, ist ein direkter Hinweis auf die Gemeinsamkeit zwischen der katholischen und der Kantischen Lehre zur "Person". In Gaudium et spes lesen wir die philosophische Auffassung der Gottebenbildlichkeit ("fecisti nos ad te”) als „Personsein“ des Menschen, die im Sinne des Königsberger Philosophen, folgendermaßen definiert wurde: »Die Würde des Menschen verlangt daher, daß er [der Mensch] in bewußter und freier Wahl handle, das heißt personal [personaliter], von innen her bewegt und geführt und nicht unter blindem innerem Drang oder unter bloßem äußerem Zwang. Eine solche Würde erwirbt der Mensch, wenn er sich aus aller Knechtschaft der Leidenschaften befreit und sein Ziel in freier Wahl des Guten verfolgt sowie sich die geeigneten Hilfsmittel wirksam und in angestrengtem Bemühen verschafft $\aleph^{15}$. Als junger Bischof aus Krakau beteiligte sich Karol Wojtyla bei den Konzilsberatungen besonders an der Vorbereitung der Pastoralkonstitution Gaudium et spes, dies beeinflusste ihn stark und der künftige Bischof von Rom hat gerade die Aussagen der Pastoralkonstitution sehr gut verinnerlicht ${ }^{16}$. Als Papst Johannes Paul II. sagt er selbst über diese Erfahrung: „Das, was das Konzil hervorhebt, ist vor allem

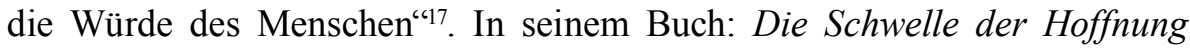
überschreiten, zitiert er „Personalität“ als Grundkategorie von Gaudium et

13 „Im Zentrum der Ethik Kants steht die Freiheit als eine absolut aufgefasste Autonomie, die den Menschen unabhängig von Gott macht“. Die Tagespost, 3.11.2004; Nr. 131, S. 10. Vgl. N. Fischer, Müssen Katholiken weiterhin Furcht vor Kant haben? Kants Philosophie als sancilla theologiae`, Katholische Universtät Eichstätt-Ingolstadt, Kastner 2005, S. 11.

${ }^{14}$ N. Fischer, Müssen Katholiken weiterhin Furcht vor Kant haben? Kants Philosophie als rancilla theologiaer, S. 11.

${ }^{15}$ Gaudium et Spes, Nr. 17.

16 „Wojtyla dimostra di aver bene integrato L'insegnamento del Concilio in particolare della Gaudium et spes". Vgl. A. Stagliano, Ecce homo. La perona, Lidea di cultura e la "questione antropologica" in Papa Wojtyla, Siena 2008, S. 26.

17 Johannes Paul II, Die Schwelle der Hoffnung überschreiten, Hamburg 1994, S. 215. 
spes: »Weil die Menschen Personen sind, d. h. mit Vernunft und freiem Willen begabt und damit auch zu persönlicher Verantwortung erhoben, werden alle - ihrer Würde gemäß - von ihrem eigenen Gewissen gedrängt und zugleich durch eine moralische Pflicht gehalten, die Wahrheit zu suchen, vor allem jene Wahrheit, welche die Religion betrifft. Sie sind auch dazu verpflichtet, an der erkannten Wahrheit festzuhalten und ihr ganzes Leben nach den Forderungen der Wahrheit zu ordnen« (Nr. 2).

Bis heute gibt es wenige Beiträge, die aus dieser Perspektive (kantische Einflüsse) das philosophische Denken von Karol Wojtyla analysieren ${ }^{18}$. Das hängt auch damit zusammen, dass trotz offensichtlicher Übereinstimmung zwischen den beiden Denkern aufgrund des oben geschilderten Misstrauens der kantischen Philosophie gegenüber fast keine Autoren eine solche Fragestellung wagten. Kant gilt für viele als Vorbote des Agnostizismus und als solcher den zentralen Gedanken des Thomismus - Gott - gefährdend. Damit wird im Gegensatz zu der denkerischen Leistung des Königsberger Philosophen, sein Anliegen vereinfacht und verzerrt. Der Kategorische Imperativ den jede menschliche Person aus eigener Erfahrung erlebt, ist nicht nur für Kant, sondern auch wie wir im vorliegenden Beitrag aufzeigen wollen, für Wojtyla der Grundstein der menschlichen Würde und explizit bei Kant eine Form der Offenbarung Gottes. Bei Wojtyla ist der gleiche Gedanke eher implizit vorhanden. Die Übereinstimmung beider Autoren bei der Auslegung der Bedingungen der Möglichkeiten menschlicher Freiheit und Sittlichkeit darzustellen, ist das Ziel der vorliegenden Arbeit.

Gott ist der zentrale Gedanke des Thomismus. Warum ist gerade der Mensch als Person (wie bei Kant) das Zentrum des philosophischen Denkens bei Karol Wojtyla? Die Ursache dafür, die Traditionsspur des Thomismus zu korrigieren, liegt sicherlich in der Berücksichtigung der neuen Entwicklungen in der Philosophie, die zwischen Mittelalter und Gegenwart unsere Kultur so stark beeinflusst haben. Robert Spaemann erklärt uns die denkerische Wende, die sich aufgrund der modernen Fortschritte in Wissenschaft und Technik ereignete folgendermaßen: ,[...] der Fortschritt der modernen Wissenschaft führte zu den Ursachen, die das Gerücht von Gott verdrängen. Das hängt einmal zusammen mit der raschen Erweiterung des Bereichs des Machbaren,

${ }^{18}$ „Interpretatorzy myśli Wojtyły przywiązują na ogół zbyt małą wagę do wpływu Kanta na uformowanie się jego antropologii filozoficznej, w szczególności jego teorii samostanowienia. Czynią tak - moim zdaniem - niesłusznie“. J. Galarowicz, Człowiek jest osoba, Kraków 1994, S. 177. 
der uns das rauschhafte und irrige Gefühl der Unendlichkeit gibt, andererseits mit der exponentiell wachsenden Geschwindigkeit der Veränderung unserer Lebensverhältnisse. Dadurch wird unsere Aufmerksamkeit so stark auf die immer neue Anpassung an die diesseitige Wirklichkeit fixiert, dass die Frage nach Grund und Sinn des Ganzen, also nach einem Außerhalb der Höhle als etwas erscheint, das wir uns nicht mehr leisten können“"19. Die neuen Herausforderungen in der Welt von heute haben den damaligen Bischof von Krakau dazu bewogen sein Hauptwerk „Person und Tat“(1969) aus der Perspektive der Erfahrung ${ }^{20}$ des Menschen zu betreiben ${ }^{21}$. Erfahrung ist für Wojtyla sehr stark mit den historischen und biografischen Aspekten verbunden. An dieser Stelle scheint es von Bedeutung zu sein daran zu erinnern, dass Wojtyla zwei Totalitarismen erlebte. Sterben und Tod seiner ganzen Familie (im Alter vom 21 ist er bereit völlig allein) ${ }^{22}$, das Leid seiner eigenen Nation, die Erlebnisse der Grausamkeiten des Krieges, die stalinistische „Befreiung“ des Landes und der kommunistische Staat nach dem Ende des Krieges weckten sein Interesse am inneren Leben d.h. an der Hinwendung zum Subjekt. Dies erklärt auch, warum der junge Wojtyla von der karmelitischen Mystik fasziniert war und zunächst seine Zukunft hinter den Klostermauern des Karmel sah. Unter diesen äußeren Bedingungen schärfte sich der Blick Wojtylas auf die anthropologischen, existenziellen Fragen und inneren Werten die „aus dem Staunen vor dem Menschen geboren“23 wurden. Auch für Kant waren die spezifischen biografischen Hintergründe relevant für seine philosophischen Fragestellungen. Was kann ich wissen? Was soll ich tun? Was darf ich hoffen? Auch Kant, ähnlich wie Wojtyla, verliert seine Mutter bereits im Kindesalter.

${ }^{19}$ R. Spaemann, ,Communio”32 (Winter 2005), Nr. 2, S. 618-636; R. Spaemann, Rationalität und Gottesglaube, http://www.kath-info.de/gottesglaube.html

${ }^{20}$ Vgl. J. Splett, Anthropologie aus christlicher Erfahrung, in: H.G. Nissing (Hg.), S. Zekorn, Staunend vor dem Menschen. Das Denken Papst Johannes Pauls II., Kevelaer 2011, S. 28-58. Kant schreibt über der reinen spekulativen Vernunft, dass wir „,nie über die Grenzen möglicher Erfahrung hinauskommen können“. B XIX. Vgl. F.W. v. Hermann, Kants Vorreden zur Kritik der reinen Vernunft, in: Fischer, Sein und Sinn der menschlichen Freiheit in der Philosophie Kants, in: $\mathrm{CH}$. Böttigheimer, N. Fischer, M. Gerwing (Hg.), Sein und Sollen des Menschen, Münster 2009, S. 30-31.

${ }^{21}$ Im gleichen Sinne, ähnlich wie Kant und Wojtyla betont heute auch Robert Spaemann, dass es ohne Erfahrung überhaupt kein Denken gibt. Vgl. R. Spaemann, Über Gott und die Welt, KlettCotta, Stuttgart 2012, S. 63.

22 Siehe: G. Weigel, Der Papst der Freiheit, Paderborn 2011.

${ }^{23}$ H.G. Nissing (Hg.), S. Zekorn, Staunend vor dem Menschen. Das Denken Papst Johannes Paul II., Kevelaer 2011, S. 13. Das Staunen ist auch nach Aristoteles Ursprung und bleibender Untergrund alles Philosophierens. Vgl. Aristoteles, Metaphysik I 2(982b11ff.). 
Er war erst dreizehn als seine Mutter im Jahre 1737 im Alter von 40 Jahren starb. Sein Vater starb neun Jahre später ${ }^{24}$. Äußerlich verläuft sein Leben innerhalb des engen Rahmens von Königsberg, wo er sich ausschließlich seiner Forschung und Lehre widmete. Ähnlich wie Wojtyla entschied er sich alleine zu bleiben, um seiner Suche nach Wahrheit, die sich als Frage: Was ist der Mensch? formulieren lässt, mehr Raum und Zeit zu geben. Die Frage nach der Wahrheit blieb auch für Wojtyla, sein Leben lang, sehr relevant. In einem Interview mit Messori auf die Frage: Was ist für Papst Johannes Paul II. der wichtigste Satz in der Bibel, antwortete Wojtyla: „Erkennt die Wahrheit und die Wahrheit wird euch befreien" (Joh 8,32) ${ }^{25}$. Freiheit, die aus der Wahrheitserkenntnis kommt, ist eine sehr kantische Auffassung ${ }^{26}$. Beide Denker betonen die Schlüsselerfahrung der inneren Freiheit des Menschen (als Gabe), die mit dem Gebrauch der eigenen Vernunft und Wahrheitssuche als Vorbedingung der Befreiung (als Aufgabe) verbunden ist. Selbst bei vielen Ähnlichkeiten bleibt zu bedenken, dass der deutsche Philosoph sich ausschließlich auf sein denkerisches Werk konzentrieren konnte (er unternahm keine Reisen, hatte einen streng geregelten Tagesablauf und verfasste seine Kritiken im Alter von ca. 60 Jahren), während Wojtyla wegen seiner zahlreichen kirchlichen Verpflichtungen für sein philosophisches Interesse weniger Zeit blieb. Als junger Bischof (mit 38 war er bereits Weihbischof von Krakau, mit 45 Erzbischof) engagierte er sich auf dem Vatikanischen Konzil, wo er sich besonders um die pastorale Konstitution Gaudium et spes (Kirche in der Welt von heute) bemühte. Kurz nach dem Konzil (1967) ist er im Alter von 47 Jahren bereits Kardinal und sein Hauptwerk „Person und Tat" schreibt er zwei Jahre später. Sicherlich waren für ihn die kulturellen Umbrüche des Jahres 1969 auch ein wichtiger Beweggrund sein Werk dem Problem des Menschen

${ }^{24}$ Nachdem die Mutter Kants, Anna Regina, im November 1735 dem Sohn Johann Heinrich das Leben schenkte, musste Sie zwei Jahre später bereits sterben. „Zwei Jahre später, am 18. Dezember 1737, im Alter von 40 Jahren, erschöpft von neun Schwangerschaften und der Belastung durch die Sorge für ihre Familie. Da Emanuel bei Tode seiner Mutter erst 13 Jahre alt war, traf ihn dieses Ereignis tief“. M. Kühn, Kant. Eine Biografie, München 2003, S. 50.

${ }^{25}$ Siehe: Johannes Paul II, Die Schwelle der Hoffnung überschreiten, Hamburg 1994.

${ }^{26}$ An dieser Stelle können wir daran erinnern, was Kant über die Aufklärung gesagt hat: „Es ist die Befreiung des Menschen aus seiner selbstverschuldeten Unmündigkeit“. Und er fügt hinzu: „Unmündigkeit ist das Unvermögen, sich seines Verstandes ohne Leitung eins anderen zu bedienen. Selbstverschuldet ist diese Unmündigkeit, wenn die Ursache derselben nicht am Mangel des Verstandes, sondern der Entschließung und des Mutes liegt, sich seiner ohne Leitung eines anderen zu bedienen“(IV, 169). Vgl. J. Schwartländer, Der Mensch ist Person, Kohlhammer Verlag 1968, S. 7. 
$\mathrm{zu}$ widmen, denn er erkannte schon damals ganz richtig, dass im Bild vom Menschen, das oft oberflächlich interpretiert wird, die Schlüsselfrage der neuen Herausforderungen für die gegenwärtige Kultur liegt.

Dieser Artikel beabsichtigt die Dynamik des Menschseins in doppelter Hinsicht darzustellen, einerseits auf Gott und andererseits auf das sich wandelnde Subjekt hin ausgerichtet. Es ergeben sich somit folgende Fragen: Gibt es Gott? Was ist das höchste Gut? Wer ist der Mensch? Ist der Mensch frei? Was soll er tun? Anhand dieser Fragen wollen wir uns dem Thema des kategorischen Imperativs als Form der Offenbarung Gottes bei Kant und Wojtyla nähern. Die Hauptabsicht unserer Ausführungen ist es die Übereinstimmung der kantischen praktischen Philosophie der Person mit Karol Wojtylas Denken aufzuzeigen. Wir wollen uns in der vorliegenden Untersuchung grundsätzlich auf Wojtylas Hauptwerk „Person und Tat“, das im Jahre 1969 entstanden ist, konzentrieren und andere Werke, wie seine Dissertation „Über den Glauben bei Johannes vom Kreuz“, sowie „Liebe und Verantwortung“ als zusätzliche Ergänzung seiner denkerischen Leistung hervorheben. Es ist deshalb verständlich, dass damit unser Augenmerk lediglich auf die Etappe bevor Karol Wojtyla zum Bischof von Rom (Johannes Paul II.) berufen wurde, beschränkt ist. Viele Interpreten versuchen die Anthropologie Wojtylas dem Thomismus zuzuschreiben. Andere bezeichnen seine Philosophie als Phänomenologie (unter dem Einfluss Max Schelers) ${ }^{27}$. Manche interpretieren die Philosophie des Papstes aus Polen als einen phänomenologischen Mittelweg, dessen reale ontologische Voraussetzungen in aristotelisch-thomistischen Fundamenten wurzeln. Es ist nicht unsere Absicht Wojtylas Philosophie als kantianisch darzustellen. Ein solches Vorhaben würde den Rahmen eines Artikels sprengen. Schon das Bemühen, das Denken des deutschen Philosophen mit dem des polnischen Papst zu vergleichen, bedeutet ein neues Feld zu betreten. Es ist ein Versuch dem positiven Signal seitens des Vatikans zu Kants Philosophie entgegenzukommen ${ }^{28}$. Bis heute fehlt es nämlich an Studien, die die Einflüsse Kants auf Wojtylas Philosophie erforschen.

${ }^{27}$ Siehe: K. Rynkiewicz, Von der Grundlegung der christlichen Ethik zur Grundlegung der philosophischen Anthropologie. Eine kritische Untersuchung zum Personbegriff bei Karol Wojtyla, Berlin 2002.

${ }^{28}$ Eine positive Stimme aus dem Vatikan zu Kant dokumentiert Norbert Fischer in seinem Vortag an der KU Eichstätt. Er spricht über die Antwort des jetzigen Papstes Benedikt XVI. auf sein Buch, das Kants Philosophie aus christlicher Perspektive aufzeigt: „Nachdem ich als Herausgeber von Kants Metaphysik und Religionsphilosophie dieses Buch Kardinal Ratzinger, dem damaligen 


\section{Gott als Grund allen Daseins}

\subsection{Kant}

Das Gottespostulat in der Kritik der praktischen Vernunft zeigt deutlich die Wichtigkeit der Frage nach Gott (und einem künftigen Leben) in der Philosophie Kants ${ }^{29}$. Bereits in der vorkritischen Zeit, wie unter anderen Aloysius Winter in seinen Forschungen gezeigt hat, gibt es viele Zugänge zu dieser Frage. In der Nova Dilucidacio schreibt Kant über die endlichen Substanzen, die dadurch in Verbindung stehen, dass sie durch den göttlichen Verstand in ihren wechselseitigen Beziehungen, dank dem gemeinsamen Grund ihres Daseins, erhalten werden ${ }^{30}$. Er schreibt dazu: „Das Ganze der Welt ist an sich selbst nichts, außer insofern es durch den Willen eines andern etwas ist ${ }^{\text {“31 }}$. Kant nennt den Raum, die omnipresencia phaenomenon, die (göttliche) Allgegenwart und die Zeit causae generalis aeternitas phaenomenon (göttliche) Ewigkeit. Zusammenfassend lässt sich leicht in seinem Denken die Hinwendung zu Gott als Grund allen Daseins und der Ermöglichung unserer Erkenntnis in Raum und Zeit feststellen ${ }^{32}$. Der Philosoph hat sogar einen eigenen Gottesbeweis zu formulieren versucht. Nach seiner Einschätzung kann er vollkommen a priori geführt werden und

Präfekten der römischen Glaubenskongregation, zugesandt hatte, erhielt ich eine Antwort, die auf ihre Weise eine unerwartete Wende im Verhältnis der Kirchenleitung zur Philosophie Kants markiert. Kardinal Ratzinger beendet sein Schreiben vom 23. März 2004 an den Herausgeber von Kants Metaphysik und Religionsphilosophie mit den Worten: „Vor allem hoffe ich, daß jüngere Philosophen und Theologen von Ihrem Buch lernen und daß ein neuer fruchtbarer Kontakt zu Immanuel Kant zustande kommt“. Vgl. Fischer, Müssen Katholiken weiterhin Furcht vor Kant haben? Kants Philosophie als >ancilla theologiae`, Katholische Universtät Eichstätt-Ingolstadt, Kastner 2005, S. 13.

${ }^{29}$ Thomas von Aqiun beginnt seine Theologische Summe von der Frage: „An Deus sit?“ „Existiert Gott?" (Vgl. I, q. 2, a. 3). Saint Thomas began his Summa Theologica with the question "An Deus sit?" - "Does God exist?" (cf. 1, q.2, a.3). Siehe mehr: http://hoye.de/gottlicht/aqproof. pdf.(19.10.12); Vgl. John Paul II, Crossing the Threshold of Hope, S. 28-29.

${ }^{30}$ A. Winter, „Es ist ein Gott denn es ist ein categ. Imperativ“. Versteckte Ansätze zur Gottesfrage in der Kritik der praktischen Vernunft, in: N. Fischer, Die Gottesfrage in der Philosophie Immanuels Kants, Herder 2010, S. 86.

${ }^{31}$ Ebenda.

$32 »$ Denn nichts ehrt Gott mehr als das, was das Schätzbarste in der Welt ist, die Achtung für sein Gebot, die Beobachtung der heiligen Pflicht, die uns sein Gesetz auferlegt, wenn seine herrliche Anstalt dazu kommt, eine solche schöne Ordnung mit angemessener Glückseligkeit zu krönen. Wenn ihn das letztere (auf menschliche Art zu reden) liebenswürdig macht, so ist er durch das erstere ein Gegenstand der Anbetung (Adoration). «I. Kant, $\mathrm{KpV}$ A 237. 
soll auch den höchsten Grad mathematischer Gewissheit innehaben ${ }^{33}$. Mit seinen ersten Formulierungen war der Autor in den sechziger Jahren nicht ganz zufrieden, weil es sich um einen bloß notwendigerweise gedachten Realgrund handelte, dessen Realität aber noch nicht erwiesen war. Diese Denknotwendigkeit konnte aber letztendlich wie er in seiner Kritik der reinen Vernunft darlegte, als Beweis nicht überzeugen, denn sein Ziel war es den Raum für den Glauben zu schaffen ${ }^{34}$ und den Übermut vieler Philosophen, die mit ihren Beweisen die Unbegreiflichkeit Gottes auf die menschliche Stufe herabwürdigten, zu bremsen. Es war auch nicht seine Absicht Gottes Existenz als solche zu leugnen, wie manche Interpreten ihm unterstellen ${ }^{35}$, sondern ihn als Inbegriff aller möglichen Prädikate überhaupt, als eine Urwirklichkeit, die nicht theoretisch bewiesen werden kann, darzustellen.

In Gott, so seine durchaus der Tradition entsprechende leitende Idee, sind Sittlichkeit und Glückseligkeit in vollkommener Weise realisiert und verbunden. Kant spricht deshalb vom ursprünglichen bzw. unabhängigen höchsten Gut, wie es in Gott als Wirklichkeit gedacht ist. Kant sieht in der Verbindung, in dem »genauen Ebenmaße« von Sittlichkeit und Glückseligkeit das höchste $\mathrm{Gut}^{36}$. In der Verwirklichung von Sittlichkeit und der Verbindung von Sittlichkeit und Glückseligkeit sieht er den einzig vernünftigen Grund einer Weltschöpfung überhaupt ${ }^{37}$. Die Pflicht zum Handeln ist bei Kant zu verstehen als ,,sich das Wohl und Heil des anderen zum Zweck zu machen“. Am Anfang des mensch-

${ }^{33}$ AA 1,395: »Datur itaque Deus et unicus, absolute necessarium possibilitatis omnis principium. [...] En demonstrationem exsistentiae divinae, quantum eius maxime fieri potest, essentialem«. Vgl. A. Winter, ,Es ist ein Gott..., S. 86.

34 „Ich mußte also das Wissen aufheben, um zum Glauben Platz zu bekommen“. BXXX; Siehe: N. Fischer (Hg.), Kants Grundlegung einer kritischen Metaphysik. Einführung in die Kritik der reinen Vernunft, Meiner Verlag Hamburg 2010, S. 32.

${ }^{35}$ In Zeitungsartikeln insinuiert Giovanni Sala SJ sogar, Kant lege Freiheit als »absolute Autonomie« aus (Die Tagespost, 3.11.2004; Nr. 131, 10): „Im Zentrum der Ethik Kants steht die Freiheit als eine absolut aufgefasste Autonomie, die den Menschen unabhängig von Gott macht“. Vgl. N. Fischer, Müssen Katholiken weiterhin Furcht vor Kant haben? Kants Philosophie als >ancilla theologiaer, Katholische Universtät Eichstätt-Ingolstadt, Kastner 2005, S. 11.

${ }^{36} \mathrm{Vgl}$. KrV A 814/B 842. Und er spricht vom abgeleiteten bzw. abhängigen höchsten Gut, wie es dem endlichen vernünftigen Weltwesen und so auch dem Menschen als vernünftiger Endzweck seines Strebens vor Augen steht. $\mathrm{KrV}$ A 810f./B 838f.

37 ,Wessen Streben durch praktische Vernunft geleitet ist, so Kant im Blick auf eine hypothetische intelligible Wahlsituation, der »würde auch wollen, daß eine Welt überhaupt existire, weil das moralische Gesetz will, daß das höchste durch uns mögliche Gut bewirkt werde «" $(R G V$ BA IX = AA 6,5), M. Forschner, Kants Gottesbild in der »Religionsschrift«, in: N. Fischer, Die Gottesfrage in der Philosophie Immanuels Kants, Herder 2010, S. 115. 
lichen Handelns steht also die Entscheidung, die Bereitschaft, die moralische Pflicht zu erfüllen, das praktische Wohlwollen im Sinne von Wohl tun. „Wenn ich andere aus Verbindlichkeit liebe, so erwerbe ich mir dadurch Geschmack an der Liebe und durch Übung wird die Liebe der Verbindlichkeit zur Neigung ${ }^{\text {“38 }}$. Wie Winter mit Recht bemerkt, heißt das zuerst Wohl tun und dann lieben, denn die Neigung kann eine gewisse Radiusbegrenzung der Wohltaten an jene die mir sympathisch sind, bedeuten. Wir können und sollen uns dem Ideal der Heiligkeit nähern, laut Kant, dazu bedürfen wir der Religion, die uns hilft unsere Pflichten als göttliche Gebote zu verstehen und sie dadurch als Motivationshilfe für unser Unvermögen anzunehmen ${ }^{39}$. Das Endgericht versteht Kant in dem Sinne, dass wir zur Antwort auf die Bedürfnisse der Leidenden aufgerufen sind. Was er hier betont, ist eine sittliche Handlung nicht mit der Hoffnung auf Belohnung zu verbinden, sondern sie soll aus dem Bewusstsein unserer moralischen Pflicht kommen. Kant kritisiert hier die kaufmännische (pharisäische) Mentalität: Ich tue etwas um belohnt zu werden. Das moralische Argument ist ,der Versuch, aus dem moralischen Zwecke vernünftiger Wesen in der Natur (der a priori erkannt werden kann) auf jene Ursache und ihre Eigenschaften zu schließen ${ }^{، 40}$. Selbstverständlich geschieht das in den Grenzen des Möglichen, also in der Reichweite unserer Vernunft, die ,die göttliche Kausalität nur nach der Analogie“" verstehen kann. Gänzlich Gott begreifen zu wollen, d.h. was er an sich selbst sei, ist eine unmögliche Aufgabe, ,ein ebenso zweckloser als vergeblicher Vorwitz ${ }^{641}$. Norbert Fischer schreibt dazu: „Sofern Menschen das oberste denkbare Gut verwirklichen sollen, sofern es ihr höchstes Ziel ist, aus Güte gut zu sein, ohne kluge Berechnung für den eigenen Vorteil, muss zwar die Vernünftigkeit des Glaubens gesichert sein, darf es aber keinerlei dogmatische Gewissheit im Blick auf die Existenz Gottes und auf den Sinn des menschlichen Lebens in der Welt geben ${ }^{642}$. In diesem Punkte stimmt Kant mit Thomas von Aquin überein, der auch sagte, dass wir mit der Kraft unser Ver-

${ }^{38}$ I. Kant, Vorlesungen über Ethik, Menzer; AA 27,250. Vgl. Winter, ,Es ist ein Gott denn es ist ein categ. Imperativ, S. 103.

${ }^{39}$ Ebenda.

${ }^{40}$ I. Kant, $K U$ B 400.

${ }^{41}$ I. Kant, $K U$ B 449.

${ }^{42}$ N. Fischer, Sein und Sinn der menschlichen Freiheit in der Philosophie Kants, in: CH. Böttigheimer, N. Fischer, M. Gerwing (Hg.), Sein und Sollen des Menschen, Münster 2009, S. 24 25. 
nunft Gott wie er ist und was er ist in seinem Wesen, nicht begreifen können ${ }^{43}$. An dieser Stelle können wir bemerken, dass es ein Fehler mancher Interpreten des Thomismus ist, z.B. seine quinque viae als fünf Gottesbeweise darzustellen. Thomas selbst spricht differenzierter und bescheidener nicht von den Beweisen Gottes, sondern von denkerischen Wegen, die uns helfen näher zu Gott zu kommen. Manche Autoren scheinen den ursprünglichen Ansatz des Meisters, auf den sie sich berufen, $z u$ verkennen und sprechen lieber von Gottesbeweisen, was an Überheblichkeit in Bezug auf die Kraft der Vernunft sogar die Aufklärungsphilosophie zu überbieten scheint. Wie die einen nur auf die Autonomie des Menschen (wo kein Platz für Gott ist) bauen und sich einseitig nur auf die Kraft der Vernunft stützen wollen, tun die anderen in Opposition zu den ersten so, als ob von der Beweisbarkeit Gottes durch die Vernunft die Existenz Gottes abhinge. Wie Norbert Fischer bewiesen hat, steht die Gottesauffassung Kants den beiden Kirchenlehrern Augustinus und Thomas von Aquin, in wesentlichen Impulsen nahe. Kant beschreibt sein Staunen über die Schönheit der Welt, was implizit auf Gottes Offenbarung in der Natur hinweist: „Die gegenwärtige Welt eröffnet uns einen so unermeßlichen Schauplatz von Mannigfaltigkeit, Ordnung, Zweckmäßigkeit und Schönheit, man mag diese nun in der Unendlichkeit des Raumes, oder in der unbegrenzten Theilung desselben verfolgen, daß selbst nach den Kenntnissen, welche unser schwacher Verstand davon hat erwerben können, alle Sprache über so viele und unabsehlich große Wunder ihren Nachdruck, alle Zahlen ihre Kraft zu messen und selbst unsere Gedanken alle Begrenzung vermissen, so daß sich unser Urtheil vom Ganzen in ein sprachloses, aber desto beredteres Erstaunen auflösen muß $\beta^{\text {‘44 }}$. Der Philosoph aus Königsberg sagt: „Denn ein Endzweck kann durch kein Gesetz der Vernunft geboten sein, ohne daß diese zugleich die Erreichbarkeit desselben, wenn

${ }^{43}$ De Deo scire non possumus quid sit, sed quid non sit. (Summa theologiae I, 3 prolog) Und weiter: „,Dies ist das Äußerste menschlichen Gotterkennens, zu wissen, dass wir Gott nicht wissen..." (Quaestiones disputatae de potentia die 7, 5 ad 14) Auch die geschaffenen Dinge sind nach Thomas unergründlich, weil alles als einem göttlichen Entwurf nachgebildet ist, der uns aber unzugänglich bleibt. Rerum essentiae sunt nobis ignotae. (Quaestiones disputatae de veritate 10,1), http://www.nwerle.at/thomasvonaquin.htm. S.th. 1, q.3, Prologus: „Sed quia de Deo scire non possumus quid sit, sed quid non sit, non possumus considerare de Deo quomodo sit, sed potius quomodo non sit“; S.th. I, q.13, a.1c; ver. q.8, a.1; q.10, a.11.: ,illud est ultimum cognitionis humanae de Deo quod sciat se Deum nescire, in quantum cognoscit, illud quod Deus est, omne ipsum quod de eo intelligimus, excedere“. Vgl. Winter, ,Es ist ein Gott denn es ist ein categ. Imperativ“, S. 104. Siehe: B. Davies, The Thought of Thomas Aquinas, Oxford 1992; G.K. Chersterton, Der Heilige mit dem gesunden Menschenverstand, Herder 1957.

${ }^{44}$ I. Kant, $K r V$ A 622/B 650. 
gleich ungewiß, verspreche und hiemit auch das Fürwahrhalten der einzigen Bedingungen berechtige, unter denen unsere Vernunft sich diese allein denken kann $^{645}$. „Und das ist nur möglich unter der Voraussetzung »eines heiligen und gütigen Welturhebers« und seiner Gebote ${ }^{\star 46}$.

\subsection{Wojtyla}

Für Karol Wojtyla ist Gott als Grund unseres Daseins ${ }^{47}$ nicht nur durch spekulative, intellektuelle Untersuchungen zu beschreiben ${ }^{48}$, sondern viel mehr durch die innere (mystische) Erfahrung. Selbstverständlich blieb der Autor von Person und Tat dem Realismus der thomistischen Auffassung der Welt

${ }^{45}$ I. Kant, $K U$ B 462 Fn. Auf die Frage eingehend: Wozu die Natur selbst existiert müssen wir es nur konsequent, mit Kant sagen, dass dazu »der Grund außer der Natur gesucht werden muß« (I. Kant, KU B 402). Vgl., B. Dörflinger, Kant über das Defizit der Physikotheologie, in: N. Fischer, Die Gottesfrage in der Philosophie Immanuel Kants, Herder 2010, S. 77.

${ }^{46}$ I. Kant, KpV A 233; A. Winter, „Es ist ein Gott denn es ist ein categ. Imperativ“. Versteckte Ansätze zur Gottesfrage in der Kritik der praktischen Vernunft, S. 98. „Gott ist jene Wirklichkeit, die dem moralischen Handeln der Menschen einen unbedingten Sinn gibt, indem er nicht nur die Verbindlichkeit der sittlichen Weltordnung garantiert, sondern auch Gesetzgeber der Weltordnung ist, d. h. die Erfüllung menschlichen Sehnens verheißt". Ch. Böttigheimer, Trinitätstheologische Ansätze in der Philosophie Kants, in: N. Fischer, Die Gottesfrage in der Philosophie Immanuel Kants, Herder 2010, S. 186.

${ }^{47}$ Die Begegnung mit dem Thomismus begann schon während seiner philosophischtheologischen Studien im Seminar und dann während der Doktorstudien in Rom. Seine Dissertation über Johannes vom Kreuz schrieb er bei dem bekannten Thomisten Réginald Garrigou-Lagrange (ein Vertreter der traditionellen Linie des Thomismus). Seine erste Lektüre war das Lehrbuch der Metaphysik, wie Wojtyla selbst zugibt, brachte ihm diese eine intellektuelle Wende. A. Frossard spricht über dieses Ereignis als kopernikanische Wende in der Begriffswelt Wojtylas. Wojtyla selbst erzählt darüber in folgender Weise: „Ich begann dieses Lehrbuch zu studieren und sofort traf ich auf große Hindernisse. Mein humanistisches, philosophisch-literarisches Denken war auf keinerlei Weise vorbereitet für die Aufnahme der Thesen und Formulierungen, die das scholastische Lehrbuch der Metaphysik von Anfang bis Ende durchzogen. Ich musste mich durchringen, durch die Menge der Sätze, Gedanken, Konzeptionen ziemlich lange konnte ich das Terrain nicht identifizieren, auf dem ich mich bewegte. Das dauerte etwa zwei Monate. Nach zwei Monaten meldete ich mich zum Examen, das ich bestand. Nach dem Examen sagte ich dem Professor, wichtiger als die Note, die ich bekomme, sei das neue Verständnis der Welt, das ich aus diesem selbständigen Ringen mit dem Lehrbuch der Metaphysik erworben habe“. A. Frossard, Nie lękajcie się. Rozmowy z Janem Pawłem, Kraków 1983. G.H. Williams, The Mind of John Paul II. Origins of his thought and Action, New Zork 1981, S. 86-90; 93-103. J. Galarowicz, Człowiek jest osoba, Kraków 1994, S. 37. Hanns-Gregor Nissing (Hg.), Einleitung und Übersetzung, in: K. Wojtyla, Wer ist der Mensch? Skizzen zur Anthropologie, München 2011, S. XIII.

${ }^{48}$ Die thomistische Reflexion bleibt deshalb für die Philosophie Wojtylas so relevant, weil sie die ganze Struktur des Kosmos, der Welt und des Menschen auf Gott hin orientiert. Gleichzeitig erkennt Wojtyla, dass der Thomismus allein nicht ausreicht, um der Dynamik der anthropologischen Frage gerecht zu werden. 
sein Leben lang treu. Auch wenn er in seinen philosophischen Schriften sich manchmal der Begriffe und Sprache anderer philosophischen Richtungen bedient, bleibt die aristotelische Sichtweise (Metaphysik) stets im Hintergrund seines Denkens. Der Thomismus orientiert die ganze Struktur des Kosmos, der Welt und des Menschen auf Gott hin und deshalb ist nach Wojtyla „die Anthropologie des hl. Thomas von Aquin tief in den Wassern dieser Tradition verankert, und sie ist gleichzeitig offen für alle Errungenschaften des menschlichen Denkens, welche die Ausarbeiten des thomistischen Konzepts der Person weiter ausfüllen und entwickeln [...] $]^{\text {449 }}$.

Schon in seiner römischen Dissertation von 1948, „Der Glaube bei Johannes vom Kreuz ${ }^{\text {“50 }}$, stellt Wojtyła fest, dass die Gottesbeziehung und der handelnde Mensch selbst in seiner Selbstbestimmung, seinen verantwortungsvollen Taten entscheidend dafür ist, dass wir überhaupt wissen, was die menschliche Person ist ${ }^{51}$. Die Entdeckung des ,inneren Menschen“, die Tiefe einer existentiellen inneren Erfahrung, lernte Wojtyla von Johannes vom $\mathrm{Kreuz}^{52}$. In seiner Beschreibung des mystischen Weges zur Vereinigung mit Gott zeigt der spanische Karmelit einerseits die Begrenztheit der Kraft der Vernunft auf dem Weg zu Gott, andererseits die Kraft des Herzens, die Liebe, die aus der Glaubensentscheidung wächst. Nach dem spanischen Mystiker begleiten den Menschen auf seinem Weg zur Vereinigung mit Gott die drei Schlüsselerfahrungen: Erkenntnis, Liebe und die Nacht. Die Erkenntnis (Vernunft) wird in Zusammenhang mit dem Glauben gestellt und die Liebe mit dem Willen. Die Nacht steht auch in Bezug zum Glauben, verstanden als ,,abismo de fe“53. Im Jahr 1951 publizierte Karol Wojtyla einen Aufsatz zum Humanismus bei Johannes vom Kreuz, und wie Jörg Splett bemerkt: „ohne das neuscholastische Korsett und schon im Titel offener den Zugang auf den Menschen zeigend“ ${ }^{\text {“54 }}$.

${ }^{49}$ K. Wojtyla, Die personale Struktur der Selbstbestimmung, in: Nissing (Hg.), Wer ist der Mensch?, S. 21.

${ }^{50}$ K. Wojtyła, Der Glaube bei Johannes vom Kreuz, Wien 1998.

${ }^{51}$ Siehe: Hanns-Gregor Nissing (Hg.), Einleitung und Übersetzung, in: K. Wojtyła, Wer ist der Mensch? Skizzen zur Anthropologie, München 2011; K. Wojtyła, Świętego Jana od Krzyża nauka o wierze, Lublin 2000.

${ }^{52}$ K. Wojtyła, Zagadnienie wiary $w$ dziełach św. Jana od Krzyża, „Ateneum Kapłańskie” 42 (1950), S. 24-42.

${ }^{53}$ K. Wojtyła, Świętego Jana od Krzyża nauka o wierze, Tow. Nauk. KUL, Lublin 2000, S. 43, 96.

${ }^{54}$ J. Splett, Anthropologie aus christlicher Erfahrung, in: H.G. Nissing (Hg.), S. Zekorn, Staunend vor dem Menschen, S. 33. 
Die Erfahrung der Nacht des Glaubens lässt sich auch im Sinne Kants, der in seiner Kritik der reinen Vernunft Platz für den Glauben schaffen wollte, übereinstimmend beschreiben. Wenn der Mensch die Insel seiner reinen Vernunft verlässt, muss er sich auf die Ungewissheit und den Abgrund des Glaubens einlassen (die Nacht bei Johannes vom Kreuz). Es erginge uns ähnlich, Johannes vom Kreuz folgend, wenn wir nachts auf einen hohen Berg kletterten, hier hilft uns unsere natürliche Kraft der Vernunft nicht mehr, die Augen sind nur für den Tag geschaffen. Wojtyla schreibt in seiner Dissertation: „Die ganze Definition der Nacht benutzt die Struktur des Glaubens, ihre innere Logik. Hier liegt die Begründung dafür warum gesagt wurde: der Glaube verdoppelt die Nacht. Gleichzeitig jedoch erklärt der Glaube die Nacht [...] Gott ist nicht ähnlich, nicht zu vergleichen mit Jemand geschaffenem, mit etwas Natürlichem, man soll also alles andere entfernen, wenn man die reine Vereinigung mit Gott sucht" ${ }^{455}$.

\section{Person und Menschenwürde}

\subsection{Kant}

Der Mensch wird für Kant als Endzweck der ganzen Schöpfung beschrieben, d.h. als Zweck ,der keinen anderen als Bedingung seiner Möglichkeit bedarf“"56. Durch die Betrachtung der Sittlichkeit, der Fähigkeit zu verantwortungsvollem Handeln, kommt Kant zu dem Ergebnis: der Mensch erweist sich in seinen freien Akten als Person und darf nicht als Mittel zum Zweck ausgenutzt (unwürdig behandelt) werden. „Nun sage ich: der Mensch und überhaupt jedes vernünftige Wesen existiert als Zweck an sich selbst, nicht bloß als Mittel zum beliebigen Gebrauche für diesen oder jenen Willen, sondern muß in allen seinen sowohl auf sich selbst, als auch auf andere vernünftige Wesen gerichteten Handlungen jederzeit zugleich als Zweck betrachtet werden. Alle Gegenstände der Neigungen haben nur einen bedingten Wert; denn, wenn die Neigungen und darauf gegründete Bedürfnisse nicht wären, so würde ihr Gegenstand ohne Wert sein. Die Neigungen selber aber als Quellen des Bedürfnisses haben so wenig einen

${ }^{55}$ K. Wojtyła, Świętego Jana od Krzyża nauka o wierze, Tow. Nauk. KUL Lublin 2000, S. 96.

${ }^{56}$ I. Kant, KUB 396; A. Winter, ,Es ist ein Gott denn es ist ein categ. Imperativ“. Versteckte Ansätze zur Gottesfrage in der Kritik der praktischen Vernunft, S. 99. 
absoluten Wert, um sie selbst zu wünschen, daß vielmehr: gänzlich davon frei $\mathrm{zu}$ sein, der allgemeine Wunsch eines jeden vernünftigen Wesens sein muß. Also ist der Wert aller durch unsere Handlung zu erwerbenden Gegenstände jederzeit bedingt. Die Wesen, deren Dasein zwar nicht auf unserem Willen, sondern der Natur beruht, haben dennoch, wenn sie vernunftlose Wesen sind, nur einen relativen Wert, als Mittel, und heißen daher Sachen, dagegen vernünftige Wesen Personen genannt werden, weil ihre Natur sie schon als Zwecke an sich selbst, d.i. als etwas, das nicht bloß als Mittel gebraucht werden darf, auszeichnet, mithin sofern alle Willkür einschränkt (und ein Gegenstand der Achtung ist) ${ }^{657}$.

Moralität ist nur durch Naturursachen nicht möglich, laut Kant, denn das „Prinzip ihrer Bestimmung zum Handeln [...] (ist) übersinnlich ${ }^{658}$. Der Mensch ist Subjekt der Moral als mit Freiheit beschenktes Wesen und „den Mechanismen der ganzen Natur" nicht unterworfen ${ }^{59}$. Durch tugendhaftes Leben soll der Mensch das höchste in der Welt mögliche Gut verwirklichen. Das höchste Gut ist, laut Kant, Endzweck Gottes „warum Gott das höchst abgeleitete Gut außer sich will, ist nicht zu fragen. Gott als höchstes Gut zu denken, oder als Urheber des höchsten Gutes, ist einerlei ${ }^{i 60}$. Der Mensch (jedes vernünftige Geschöpf) ist als Subjekt des moralischen Gesetzes zu verstehen ${ }^{61}$. Er ist Zweck an sich selbst und in seiner Autonomie der Freiheit orientiert, das moralische Gesetz, welches heilig ist, laut Kant, zu verwirklichen. Die Person hat nicht nur einen relativen Wert, das heißt einen Preis, sondern einen inneren Wert, das ist ihre Würde ${ }^{62}$. Der Mensch ist mit Würde ausgestattet,

${ }^{57}$ I. Kant in H.J. Türk /W. Trutwin (Hrsg.), Philosophisches Kolleg 4, Anthroplogie, Düsseldorf 1978, S. 32.

${ }^{58}$ I. Kant, KUB 400Fn.

${ }^{59}$ Ebenda.

${ }^{60}$ I. Kant, Metaphysik K2; AA 28,810.

${ }^{61},[. ..] \gg$ der Mensch, der doch allein den letzten Endzweck von allem diesem in sich enthalten kann, das einzige Geschöpf sein, das davon ausgenommen wäre«, weil das moralische Gesetz in ihm [...] so weit über allen Nutzen und Vortheil« hinausgeht, daß er auf viele Annehmlichkeiten verzichten muß“, I. Kant, $\mathrm{KrV}$ B 425f. A. Winter, ,Es ist ein Gott denn es ist ein categ. Imperativ“. Versteckte Ansätze zur Gottesfrage in der Kritik der praktischen Vernunft, S. 100.

${ }^{62}$ Der Mensch hat »nicht bloß einen relativen Werth, d. i. einen Preis, sondern einen innern Werth, d. i. Würde«; Würde hat, was »absoluten Werth hat« und »kein Aequivalent verstattet« I. Kant, GMS BA 77.65.77 = AA 4,435.428.434). A. Winter, ,Es ist ein Gott denn es ist ein categ. Imperativ“. Versteckte Ansätze zur Gottesfrage in der Kritik der praktischen Vernunft, S. 101. Die moderne Bedeutung der Würde des Menschen wurde wesentlich durch wichtige rechtliche und politische Regelungen des 20. Jahrhunderts geprägt, darunter die Präambel der Charta der Vereinten 
die unantastbar ist und deshalb verdient er seitens aller vernünftiger Wesen Achtung. In diesem Moment sehen wir die Fundamente der Gleichheit aller Menschen, die übereinstimmend mit dem Bild der Erschaffung des ersten Menschen aus der Bibel (Genesis) sind. Die Philosophie Kants betont in ihren wesentlichen Elementen die Person als zu freien Taten bestimmt und damit würdig, was mit dem christlichen Bild vom Menschen übereinstimmt.

Im Einklang mit dem biblischen Liebesgebot sieht er das moralische Gesetz „liebe Gott über alles und deinen Nächsten wie dich selbst“". Es geht dabei aber nicht um die Neigung als Motiv, weil in der Auffassung Kants Gott nicht der Gegenstand unserer Sinne ist, man kann auch keinen Menschen auf Befehl lieben, es geht vielmehr um ,die praktische Liebe, die in jenem Kern aller Gesetze" gemeint ist.

\subsection{Wojtyla}

In der Einführung zu seinem Hauptwerk schreibt Wojtyla: „,Der Gegenstand der Studie ist also die Person, die sich in der Tat erschließt [...]. Deshalb bringt die Person also nicht nur ihre Transzendenz in der Tat zum Vorschein, sondern auch die für die Tat charakteristische Integration; die dynamische Wirklichkeit der Tat konstituiert sich in dieser Integration und nicht außer ihr oder über ihr. Die Person, die sich durch die Tat zur Erscheinung bringt, durchdringt und umfasst zugleich die ganze psychosomatische Struktur des eigenen Subjekts ${ }^{\text {“63. }}$.

Die menschliche Person ist die erste Wirklichkeit, sie ist fundamental und steht als Erstes Sein $^{64}$, erst dann sprechen wir nach Wojtyla von zwischenmenschlichen Relationen und der Gesellschaft. Die Erfahrung des Menschen und insbesondere der Tat einer Person ist nach Wojtyla ein

Nationen von 1945, die Präambel und Art. 1 der Allgemeinen Erklärung der Menschenrechte von 1948 und Art. 1 Abs. 1 des Grundgesetzes der Bundesrepublik Deutschland von 1949. Vgl.H. Dreier, Grundgesetz, 2. Aufl., Tübingen 2004.

${ }^{63}$ K. Wojtyła, Person und Tat, Herder 1981, S. 346.

${ }^{64}$ Thomas von Aquin nimmt als Ausgangspunkt seiner Analyse des Menschen Boetius Definition der Person. Er spricht über die Person als Individuum mit vernünftiger Natur, erste Substanz, suppositum rationale. Thomas definiert folgendermaßen: „Die Person ist Substanz rationaler Natur". Die Person ist ein substantielles Wesen, d.h. innerlich einheitlich, das Fundament für die Akzidentien. Person als Substanz ist ein konkretes Wesen, einheitlich und individuell. Sie ist fähig zum schöpferischen Denken, der Erkenntnis der Wahrheit, vor allem der Wahrheit über das Gute, sie ist ebenso fähig zu autonomem Handeln. Ontischer Aspekt des Menschenwesens wurde mit dem Begriff suppositum bezeichnet. Als suppositum ist der Mensch das reale Subjekt der Existenz und des Handlens. Vgl. Cz. Bartnik, Personalizm, Lublin 2000, S. 90-92. 
besonderer Moment, in dem wir die Person in ihrer Autonomie (Freiheit und Verantwortlichkeit) erkennen können.

So wie die thomistische Interpretation den Menschen in einem ordo socialis, in einer gewisse Unbeweglichkeit und Statik beschrieb, versucht der Denker aus Krakau die Perspektive zu wenden und den Reichtum des Menschen durch seine aktive, ihm eigene Handlung zu zeigen. Die anthropologische Frage, die schon Immanuel Kant als zentrale Frage ${ }^{65}$ der Philosophie beschreibt: „Wer ist der Mensch?““ ist die Hauptfrage aller philosophischen Untersuchungen auch für Karol Wojtyla ${ }^{66}$. Als Antwort auf die oben gestellte Frage formuliert er anknüpfend an Kant: der Mensch ist eine Person ${ }^{67}$. Seine Würde ist einzigartig und einmalig und unveräußerlich, unabhängig von den Umständen seiner Existenz $^{68}$. Was im Menschen unreduzierbar ist, ist die Perspektive, die ihn gleichzeitig als Subjekt und Objekt der Erfahrung begleitet (Selbstbewusstsein) ${ }^{69}$. „So schöpfen wir aus dem menschlichen ,operari“ nicht nur die Erkenntnis, dass der Mensch „Subiekt“ seines Handelns ist, sondern

${ }^{65}$ Kant betont, dass der Mensch unter zwei Blickwinkeln (Leib und Seele) zu betrachten ist, sie folgen aus der Beantwortung der drei Fragen:1. Was kann ich wissen? 2. Was soll ich tun? 3. Was darf ich hoffen?“. I. Kant, Kritik der Reinen Vernunft, Köln 2011, B832f. Als vierte Frage fügt er bei: „Was ist der Mensch?“. Dazu sagt er: „Die erste Frage beantwortet die Metaphysik, die zweite die Moral, die dritte die Religion, und die vierte die Anthropologie“. N. Fischer schreibt dazu: Kant denkt den Menschen als Wesen der Metaphysik, der Moral und die Religion (Logik A 25) und kann damit als ein Philosoph gelten, der sich in hervorragender Weise um die philosophischen Grundfragen der (christlichen) Theologie bemüht hat (wovon er auch selbst gesprochen hat)". N. Fischer, Sein und Sinn der menschlichen Freiheit in der Philosophie Kants, in: Ch. Böttigheimer, N. Fischer, M. Gerwing (Hg.), Sein und Sollen des Menschen, Münster 2009, S. 26.

${ }^{66}$ K. Wojtyła, A. Szostek, T. Styczeń, Der Streit um den Menschen. Personaler Anspruch des Sittlichen, Kevelaer 1979.

${ }^{67}$ J. Galarowicz, Człowiek jest osobą, Kraków 1994; J. Schwartländer, Der Mensch ist Person, Mainz 1968.

${ }^{68}$ „Ein jeder Mensch“, schreibt Kant in der Metaphysik der Sitten, 2. Teil, § 38, „hat rechtmäßigen Anspruch auf Achtung von seinen Mitmenschen, und wechselseitig ist er dazu auch gegen jeden anderen verbunden“. I. Kant, Metaphysik der Sitten, 2. Teil, A 139, in: W. Weischedel (Hg.), Immanuel Kant. Werke in sechs Bänden, Wissenschaftliche Buchgesellschaft, Darmstadt (1956-1964), Bd. 4, S. 600. „Achtung geht jederzeit auf Personen, niemals auf Sachen“, I. Kant, Kritik der Praktischen Vernunft A, S. 35. Siehe: N. Fischer, Sein und Sinn der menschlichen Freiheit, S. 31.

69, ,...] świadomości zawdzięcza człowiek upodmiotowienie tego co przedmiotowe”, K. Wojtyła, Osoba i czyn oraz inne studia antropologiczne, Towarzystwo Naukowe KUL, Lublin 2000, S. 91. Vgl. Hanns-Gregor Nissing (Hg.), Einleitung und Übersetzung, in: K. Wojtyła, Wer ist der Mensch? Skizzen zur Anthropologie, München 2011, S. I-XVI. Siehe: K. Wojtyła, Subjectivity and Irreducible in Man, "Analecta Husserliana”, Vol. VII, 1978. (,Subjektivität und das Unreduzierbare" im Menschen), in: Nissing (Hg.), Wer ist der Mensch?, S. 3-12. 
auch, wer er als Subiekt seines Handelns ist ${ }^{\text {"70 }}$. Das Axiom operari sequitur esse wird umgedreht. Dies ist „eine andere Richtung der Erfahrung und des Verstehens", schreibt Wojtyla. Es geht um die Erschließung der Person in der Erfahrung des Handelns (Tat) oder, wie William J. Hoye sagt, es geht um die Erforschung der Tat, insofern sie die Person erklärt ${ }^{71}$. Ähnlich wie später Robert Spaemann, betont der Autor von Person und Tat Kant folgend, dass der Mensch „Jemand“ und nicht „Etwas“ ist ${ }^{72}$. Die Person-Würde des Menschen ist deshalb unantastbar, was nicht nur auf das göttliche Fundament (fecisti nos ad te) zurückzuführen ist, sondern auch rein philosophisch gesehen Ursprung und Quelle menschengerechter Auffassung darstellt. Karol Wojtyla unterstreicht diese, jedem Menschen zustehende Würde, einerseits philosophisch, andererseits theologisch. Philosophisch bedeutet es, dass jeder Mensch seine ihm eigene unantastbare Würde auf der Grundlage seines Menschseins besitzt, theologisch hängt unsere Würde u.a. mit der Menschwerdung Jesu Christi zusammen „das Geheimnis des Menschen ist zugleich Teil des Geheimnisses Gottes und der Schöpfung “73. Die Beziehung des Menschen zu seinem Schöpfer ist zunächst personaler Art: Ich - Du, ähnlich wie zu einem Mitmenschen. Wojtyla bezeichnet diese gegenseitige Hingabe auch als Dienst an der Person. In dieser personalen Kommunikation zeigt sich eine Wirklichkeit, die eigentlich ein Mysterium ist. Es ist die Verwirklichung des menschlichen Daseins als Wesen, das Verlangen nach wahrer Liebe in sich trägt und nur im gegenseitigen Verschenken von Natur aus zu finden ist. „Der Mensch kann nicht ohne Liebe leben. Er bleibt für sich ein unbegreifliches Wesen, sein Leben ist ohne Sinn, wenn ihm nicht die Liebe geoffenbart wird“74. Wojtyla beschreibt - im Sinne Kants- die moralische Pflicht (praktische Liebe) der Person gegenüber dem anderen $\mathrm{Du}^{75}$.

${ }^{70}$ K. Wojtyła, Person und Tat (Anm.1), S. 19. In der Handlung gewinnt der Mensch die Erkenntnisse über sich selbst. Vgl. W.J. Hoye, Abhängigkeit in der Wahrheit. Der Mensch und das Gute bei Karol Wojtyla/Johannes Paul II, in: H.G. Nissing (Hg.), S. Zekorn, Staunend vor dem Menschen. Das Denken Papst Johannes Pauls II., Kevelaer 2011, S. 82.

${ }^{71}$ W.J. Hoye, Abhängigkeit in der Wahrheit, S. 82.

${ }^{72}$ R. Spaemann, Personen. Versuche über den Unterschied zwischen ,etwas “ und ,jemand “, Klett-Cotta, Stuttgart 1996.

${ }^{73}$ K. Wojtyła, Osoba i czyn, Kraków 1985, S. 127.

${ }^{74}$ Johannes Paul II., Redemptor hominis, Rom 1979, Nr. 10.

75 „Der Mensch bestätigt sich selbst auf vollkommenste Weise in der Hingabe seiner selbst. Dies ist die volle Verwirklichung des Gebotes der Liebe“. „Wenn wir die menschliche Freiheit dieser Perspektive berauben, wenn der Mensch sich nicht um die Hingabe seiner selbst an die 
The Person and the Challenges
Volume 3 (2013) Number 1

Es ist die moralische Verpflichtung das praktische Wohlwollen im Sinne von Wohl tun zu wollen und zu erfüllen: „Die Liebe einer Person zu einer anderen muss wohlwollend sein, um wahr zu sein, sonst wäre sie nicht Liebe, sondern bloß Egoismus ${ }^{676}$.

\section{Das Höchste Gut und unsere Bestrebung (das moralische Gesetz)}

\subsection{Kant}

In der Kritik der reinen Vernunft schreibt Kant: „Auf solche Weise führt das moralische Gesetz durch den Begriff des höchsten Guts, als das Object und den Endzweck der reinen praktischen Vernunft, zur Religion, d. i. zur Erkenntni $\beta$ aller Pflichten als göttlicher Gebote, nicht als Sanctionen, d. i. willkürliche, für sich selbst zufällige Verordnungen eines fremden Willens, sondern als wesentliche Gesetze eines jeden freien Willens für sich selbst, die aber dennoch als Gebote des höchsten Wesens angesehen werden müssen“77.

Wie Norbert Fischer feststellt, sieht Kant im guten Willen das oberste Gut, ähnlich wie Augustinus. „Augustinus denkt den guten Willen wie Kant als

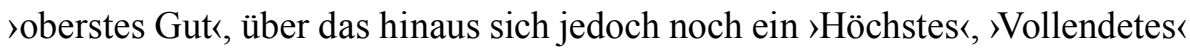
denken läßt"“78.

Kant erinnert an die alte Formel: „nihil appetimus, nisi sub ratione boni, nihil aversamur, nisi sub ratione mali“. Der Mensch verlangt nach dem Guten, wenn er es als Gutes begreift und meidet das Böse aus dem gleichen Grund. Der Begriff des Guten ist übereinstimmend mit der klassischen Philosophie der Grund für das Begehren des Willens. Kant unterscheidet dabei, dass das Wohl oder Übel sich auf die sinnlichen Gefühle beziehen, die Lust oder Unlust, das Gute dagegen und das Böse betreffen den Willen. Deshalb gilt das moralische Gesetz als alleiniger Bestimmungsgrund des Willens (a priori und rein formal). „Das praktische Gesetz (ist zu verstehen) als Bedingung der Möglichkeit“ trotz

anderen bemüht, so kann diese Freiheit zur Gefahr werden“. Johannes Paul II, Die Schwelle der Hoffnung überschreiten, Hamburg 1994, S. 227.

${ }^{76}$ K. Wojtyła, Liebe und Verantwortung. Eine ethische Studie, München 1981, S. 72.

${ }^{77}$ I. Kant, $K r V$ A 233.

${ }^{78} \mathrm{Vgl}$. KpV A 198. N. Fischer, Der menschliche Wille als scausa primar. Augustins Radikalisierung der Freiheitsproblematik., Vom Rang und vom Sinn der Gottesfrage in der Philosophie Kants, in: Ch. Böttigheimer, N. Fischer, M. Gerwing (Hg.), Sein und Sollen des Menschen, Münster 2009, S. 8. 
der Abhängigkeit von den Naturgesetzen dem freien Willen zu folgen. Nur das Handeln , aus Pflicht, d.i. aus Achtung fürs Gesetz hat moralischen Wert" ${ }^{\text {“79 }}$. Der Gegenstand der reinen praktischen Vernunft ist das höchste Gut.

Für den Begriff des höchsten Gutes (summum bonum metaphysicum) entwirft Kant seine originelle Terminologie: „Glückseligkeit also in dem genauen Ebenmaße mit der Sittlichkeit der vernünftigen Wesen, dadurch sie derselben würdig sind, macht allein das höchste Gut einer Welt aus, darin wir uns nach den Vorschriften der reinen, aber praktischen Vernunft durchaus versetzen müssen, und welche freilich nur eine intelligibele Welt ist, da die Sinnenwelt uns von der Natur der Dinge dergleichen systematische Einheit der Zwecke nicht verheißt, deren Realität auch auf nichts andres gegründet werden kann, als auf die Voraussetzung eines höchsten ursprünglichen Guts“80.

Das höchste Gut differenziert Kant in zwei Arten: a) als das oberste Gut (,Tugend als Würdigkeit glücklich zu sein“) und b) als das consumatum, als vollendetes Gut, die Glückseligkeit in einer Proportion zur Tugend. Für den Philosophen aus Königsberg ist die Verwirklichung des höchsten Gutes in der Welt das „notwendige Objekt, eines durch moralischen Gesetz bestimmbaren

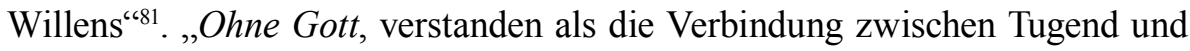
Glückseligkeit, wie oben dargestellt, würde es eine leere Idee seyn ${ }^{\text {“82 }}$. In diesem Fall würde das moralische Gesetz an sich falsch und widersprüchlich sein, laut

${ }^{79}$ I. Kant, GMS IV 398.

${ }^{80}$ I. Kant, $K r V$ A 814/B 842; der Abschnitt hat den Titel (A 804/B 832): Von dem Ideal des höchsten Guts, als einem Bestimmungsgrunde des letzten Zwecks der reinen Vernunft. Vgl. A. Winter, „Es ist ein Gott denn es ist ein categ. Imperativ“. Versteckte Ansätze zur Gottesfrage in der Kritik der praktischen Vernunft, in: N. Fischer, Die Gottesfrage in der Philosophie Immanuels Kants, Herder 2010, S. 97.

${ }^{81}$ I. Kant, $K p V$ A 219. Ausführlicher wird der Gottesbezug der Pflicht in der Kritik der Urteilskraft bestätigt (KU B 476f.): »Die moralische Teleologie« führt, weil »sie a priori auf von unserer Vernunft untrennbaren Principien beruht, [...] auf einen bestimmten Begriff der obersten Ursache als Weltursache nach moralischen Gesetzen, mithin einer solchen, die unserm moralischen Endzwecke Genüge thut: wozu nichts weniger als Allwissenheit, Allmacht, Allgegenwart usw. als dazu gehörige Natureigenschaften erforderlich sind, die mit dem moralischen Endzwecke, der unendlich ist, als verbunden, mithin ihm adäquat gedacht werden müssen, und kann so den Begriff eines einzigen Welturhebers, der zu einer Theologie tauglich ist, ganz allein verschaffen. // Auf solche Weise führt eine Theologie auch unmittelbar zur Religion, d. i. der Erkenntniß unserer Pflichten als göttlicher Gebote, weil die Erkenntniß unserer Pflicht und des darin uns durch Vernunft auferlegten Endzwecke den Begriff von Gott zuerst bestimmt hervorbringen konnte, der also schon in seinem Ursprunge von der Verbindlichkeit gegen dieses Wesen unzertrennlich ist $\ll$. Zit. nach A. Winter, ,Es ist ein Gott denn es ist ein categ. Imperativ“, S. 102.

${ }^{82}$ I. Kant, KpV, 137 f.; A. Winter, ,Es ist ein Gott denn es ist ein categ. Imperativ“, S. 98. 
Kant. Es ist deshalb notwendigerweise anzunehmen, dass das moralische Gesetz in seiner Ausrichtung auf das höchste Gut zu verstehen ist. „Ohne also einen Gott und eine für uns jetzt nicht sichtbare, aber gehoffte Welt sind die herrlichen Ideen der Sittlichkeit zwar Gegenstände des Beifalls und der Bewunderung, aber nicht Triebfedern des Vorsatzes und der Ausübung, weil sie nicht den ganzen Zweck, der einem jeden vernünftigen Wesen natürlich und durch eben dieselbe reine Vernunft a priori bestimmt und notwendig ist, erfüllen" ${ }^{\text {" } 83}$. Dieser Zusammenhang besteht nicht nur objektiv, „das moralische Gesetz gebietet, das höchste möglich Gut in einer Welt mir zum letzten Gegenstandes alles Verhalten zu machen“64. Das höchste Gut (auch meine eigene Glückseligkeit) ist damit als Gegenstand aller unserer Bestrebungen zu verstehen ${ }^{85}$.

Die Ehre Gottes geschieht für Kant „durch Handlung und Tat" ${ }^{\star 86}$. „Das Princip: handle in Beziehung auf ein jedes vernünftige Wesen (auf dich selbst und andere) so, daß es in deiner Maxime zugleich als Zweck an sich selbst gelte, ist demnach mit den Grundsatze: handle nach einer Maxime, die ihre eigene allgemeine Gültigkeit für jedes vernünftige Wesen zugleich in sich enthält, im Grunde einerlei“"87.

Kant lehnt einen voluntaristischen Nominalismus ab, d.h. eine Vorstellung, bei der Gott beliebig festgesetzt hat, was als Gut und was als Böse gelten soll. Der Philosoph unterstreicht, dass „das moralische Gesetz für den Willen eines allervollkommensten Wesens ein Gesetz der Heiligkeit“ ist. Für Kant ist die Verwirklichung des höchsten Gutes ein Objekt eines durch das moralische Gesetz gelenkten Willens. Kant spricht über eine notwendige Voraussetzung „eines heiligen und gütigen Welturhebers" ${ }^{\text {"88 }}$. Die Kantische formalistische Ethik hat also auch eine Orientierung am Guten, das als höchstes Gut zu verstehen ist und als a priori notwendig gedacht wird. Das moralische Gesetz macht es uns zur Pflicht das höchste Gut ,zum Gegenstande unserer Bestrebungen zu setzen“89. Für Kant ist das moralische Gesetz nicht nur formaler, sondern auch materialer Bestimmungsgrund ,der Gegenstände der

\footnotetext{
${ }^{83}$ I. Kant, $K p V$ A 226; Vgl. I. Kant, $K r V$ A 813/B841.

${ }^{84}$ I. Kant, $K p V$ A 233.

${ }^{85}$ Ebenda.

${ }^{86}$ A. Winter, „Es ist ein Gott denn es ist ein categ. Imperativ“, S. 100.

${ }^{87}$ I. Kant, GMS BA 82 = AA 4,437. Vgl. A. Winter, S. 101.

${ }^{88}$ I. Kant, KpV A 233.

${ }^{89}$ Ebenda.
} 
Handlung unter dem Namen des Guten und Bösen“"90. Das höchste Gut ist in der Welt nur möglich ,sofern eine oberste Ursache der Natur angenommen wird, die eine der moralischen Gesinnung gemäße Kausalität hat ${ }^{\star 91}$. „Also ist die oberste Ursache der Natur, sofern sie zum höchsten Gute vorausgesetzt werden muß, ein Wesen, dass durch Verstand und Willen die Ursache (folglich der Urheber) der Natur ist, das ist Gott" ${ }^{\star 92}$.

\subsection{Wojtyla}

Für Kant ist die höchste Ehre Gottes, die ihm ein Mensch erweisen kann, durch die Tat möglich. Es ist besonders wichtig in Bezug auf das Denken von Wojtyla, der in seinem Hauptwerk gerade die Tat hervorhebt, als ein Wesenselement der Würde der Person. Die Befähigung zur freien, verantwortungsvollen, selbstbestimmenden Tat ist für Wojtyla ein Zeichen der Unantastbarkeit der Personenwürde und für Kant (ähnlich wie bei Augustinus und Thomas) eine Bestimmung jeder Person zur Realisierung des höchsten Gutes. In seinen Ausführungen über die Urheberschaft der Person legt Wojtyla einen besonderen Schwerpunkt auf das Gewissen ${ }^{93}$. In der vertikalen Transzendenz betont Wojtyla die Rolle des Gewissens als „Stimme Gottes“994 und Gesetzgeber der Person ${ }^{95}$, das dem Subjekt beim Urteilen hilft ${ }^{96}$. In seinem Bezug zur Wahrheit und zum Guten wurzelt sein Urteilscharakter. Die Tat ist immer eine spezifische Synthese der Dynamik des Menschen: neben dem eigenen Willen spielen auch somatische und psychische Elemente eine Rolle. Sie (die Tat) wird konstituiert neben der Transzendenz auch durch

${ }^{90}$ Der erste Bestimmungsgrund hat für ihn den Primat, auch wenn es den Menschen nicht gelingt das so bestimmte höchste Gut zu verwirklichen, muss er sich auch das summum bonum verlassen.

${ }^{91}$ I. Kant, $K p V$ A $225 f$.

92 Ebenda.

${ }^{93}$ Das Gewissen ist in einem bestimmten Sinn der letzte Gesetzgeber und Richter der Person. „Odpowiedzialność przed kimś, zintegrowana w głosie sumienia stawia moje własne $j a \mathrm{w}$ pozycji sędziego w stosunku do mojego własnego ja". K. Wojtyla, Osoba i czyn, Lublin 2000, S. 215.

94 „Die Würde der menschlichen Person findet ihre volle Bestätigung in der Tatsache der Offenbarung selbst. Diese Tatsache nämlich bedeutet: die Anknüpfung einer Beziehung zwischen Gott und dem Menschen. Dem Menschen, den Er zu seinem Bilde schuf, überträgt Gott seine Gedanken und Vorhaben“. K. Wojtyla, Von der Königswürde des Menschen, Stuttgart 1980, S. 46.

${ }^{5}$ Über Stimme des Gewissens bei Kant. Vgl. I. Kant, KpV A 175f.

${ }^{96}$ Das Gewissen ist quasi der letzte Gesetzgeber der Person, gleichzeitig ist es kreativ im Bereich der Applikation der Normen. K. Wojtyła, Osoba i czyn oraz inne studia antropologiczne, Towarzystwo Naukowe KUL, Lublin 2000, S. 173. 
die Integration ${ }^{97}$. In diesem Sinne steht jede Entscheidung im Zusammenhang mit der Selbstverwirklichung.

Der Wille ist für Wojtyla ebenso wie für Kant sehr relevant ${ }^{98}$. Ohne den freien Willen können wir nicht über die Selbstbestimmungsfrage sprechen. Die innere Erfahrung zeigt uns, laut Wojtyla, dass der Mensch handelt, d.h. sich aus eigenem Verantwortungsbewusstsein für gewisse Taten (böse oder gute) entscheiden kann und dadurch auch als freies Wesen sich selbst nicht nur reflektiert, sondern sich gleichzeitig auch gut oder schlecht macht. Christoph Böhr erinnert in seinem Artikel „Metaphysik nach der Postmoderne“ an Wojtylas Auffassung dieser Erkenntnis: „Die Rede ist hier von den Erkenntnissen, derer wir im Gewissen habhaft und gewiss werden, bevor ein Handeln einsetzt. Die wichtigste dieser Erkenntnisse des Gewissens ist, dass es offenbar ein Sein - ein unbedingtes Sein - jenseits dessen gibt, was wir als Erkenntnis selbst in uns hervorbringen. Immer dann, wenn uns in völliger Klarheit vor Augen steht, so oder anders entscheiden zu können, wird uns schlagartig bewusst, was es heißt, frei zu sein. Karol Wojtyla hat sich diesem Zusammenhang in seiner philosophischen Hauptschrift „Person und Tat“ gewidmet: „Die Freiheit veranschaulicht sich für jeden Menschen am eigentlichsten in einem Erleben, das man zusammenfassen kann in dem Satz: ,Ich kann - aber ich muss nicht'. Das ist nicht nur ein Bewusstseinsinhalt, sondern eine Erscheinung des dem Menschen eigenen Dynamismus ${ }^{\text {“999. }}$

${ }^{97}$ Der Autor betont die folgenden Prioritäten und Hierarchien: Transzendenz gegenüber der Integration, Psyche gegenüber der Soma, Emotivität gegenüber Reaktivität.

${ }^{98}$ Gerade durch die Kritik an Max Scheler Emozionalismus und die Unterschätzung der Freiheitsproblematik sehen wir, dass Wojtyla die Rolle des Wollens Kants folgend hervorhebt. Über den Einfluss Max Schelers (Bedeutung der Gefühle) auf den Personbegriff Wojtylas schreibt K. Rynkiewicz ausführlich in seiner Dissertation, Von der Grundlegung der christlichen Ethik zur Grundlegung der philosophischen Anthropologie. Eine kritische Untersuchung zum Personbegriff bei Karol Wojtyla, Berlin 2002. „Woran lässt sich die Relevanz der schelerschen Wertauffassung für den Begriff der Person bei Wojtyla erkennen? Zunächst einmal ist festzuhalten, dass nur die Person im schelerschen System der ,Träger“ von den Werten „gut“ und „böse“ ist, selbst wenn sie anders als bei Wojtyla aufgefasst wird. Darüber hinaus wird diese Relevanz auch schon durch Wojtylas scharfe Kritik an Scheler selbst zum Ausdruck gebracht, deren Folge die Feststellung ist, dass die von Scheler herausgearbeitete phänomenologische Theorie sittlicher Werte keinesfalls einwandfrei und in dieser Form auf die gleiche Diskussionsebene mit der Konzeption der Person unseres Autors zu stellen sei“. Ebenda, S. 28. „Was die erste Frage betrifft, steht es außer Zweifel, dass der Schwerpunkt der Kritik Wojtylas an Scheler sich auf die Rolle des Wollens in dessen System konzentriert (das Wollen ist eine notwendige Komponente der Konzeption der Person bei Wojtyla). Das Wollen war für Scheler nur ein Epiphänomen des Gefühlslebens“.

${ }^{99}$ Ch. Böhr, Metaphysik nach der Postmoderne, Die Tagespost (28.08.2012), Nr. 103, S. 9. 


\section{Die Erfahrung der Pflicht als Freiheitsbeweis}

\subsection{Kant}

Der Mensch beurteilt was kategorisch gut ist, indem er, laut Kant, sich an die Stelle der anderen Person versetzt. Das Bewusstsein einer Pflicht ${ }^{100}$ bezeichnet der Philosoph als Faktum der Vernunft. Was ist die Voraussetzung dieses Faktums? Wie wir schon in der Kritik der reinen Vernunft lesen können, spricht der Autor über die eschatologische Perspektive, als Ursprung des moralischen Pflichtbewusstseins. Dieses Faktum der Vernunft, das sich uns allen ,aufdringt als synthetischer Satz a priori“"101 und das ,apodiktisch gewiss“"102 ist, schließt jede Beliebigkeit aus aufgrund seines verpflichtenden Charakters. In der ersten Fassung formuliert Kant seinen Imperativ folgendermaßen: „Handle nur nach derjenigen Maxime, durch die du zugleich wollen kannst, daß sie ein allgemeines Gesetz

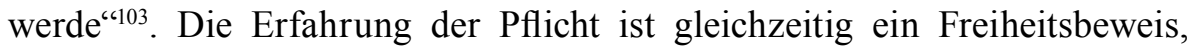
wie Aloysius Winter beschreibt „ratio conoscendi“ der Freiheit ${ }^{104}$. Für alle Personen gilt das „Faktum der Vernunft“ - die ,[...] Bedingung des sittlich Verpflichtetseins ist" ${ }^{\text {"105. }}$. Das versuchen manche Interpreten passiv als von der Vernunft gemacht zu verstehen, was aber nicht im Sinne Kants denkerischer Leistung geschieht, denn in solchen Interpretationen wäre ein Rückschluss auf die Freiheit nicht möglich. Mit welcher Autorität fordert das Sittengesetz den Menschen heraus? Auf diese Frage kann man auf zweierlei Arten antworten: 1. Im Sinne der klassischen Philosophie, die auch mit dem christlichen Glauben übereinstimmt, ist die göttliche Macht die höchste Autorität, die das Sittengesetz vor den Menschen formuliert hat. Der Mensch ist lediglich der Empfänger, der dieses Gesetz als Sollen erkennt. 2. Im Sinne der materialistischen Philosophie, die die Gottesfrage verleugnet, wird der

${ }^{100}$ Die Bestimmung des Menschen als Ziel - und nicht als Mittel - besagt eben das: dass er nicht zu einem Gebrauchsgegenstand degradiert werden darf. Kant wollte sich damit dem angelsächsischen Utilitarismus widersetzen.

${ }^{101}$ I. Kant, $K p V$ A 163; 56.

${ }^{102}$ I. Kant, KpV A 81.

${ }^{103}$ I. Kant, AA 0004IV, 421.

${ }^{104}$ A. Winter, „Es ist ein Gott denn es ist ein categ. Imperativ“, S. 89.

${ }^{105}$ „Die Sollenserfahrung ist ratio cognoscendi der Freiheit, die umgekehrt als ratio essendi nicht Ursache, sondern Bedingung des sittlichen Verpflichtetseins ist und als solche a priori gedacht werden muss“. Ebenda. 
Mensch als völlig autonomer Autor des Sittengesetzes interpretiert. Der Autor der Kritiken spricht von der Autorität der Heiligkeit, „das unendliche Wesen als oberste Intelligenz", das keiner moralischen Nötigung unterliegt, die über „alle(n) Wesen die Vernunft und Willen haben“, steht. Der Schöpfer der Welt, intellectus originarius, ist „der Grund und das Prinzip aller Möglichkeit“"106. Der Vater des moralischen Gesetzes, dem alle freien Wesen unterworfen sind, ist der "heilige Gesetzgeber"107. In diesem Zusammenhang lautet die relevante Frage für Kant: „wie wir als eingeschränkte Menschen solcher heiliger Gesetze fähig sind“108. Deshalb ist der Mensch im Unterschied zu allen anderen Wesen als Zweck an sich selbst zu definieren, der nie als ein Etwas, als ein Ding gebraucht werden darf. Gott wird bei Kant als „Höchster Gesetzgeber" und ,heiliger moralischer Weltherrscher" definiert, sein Gesetz liegt auch dem einfachsten Menschen so nahe ,als ob es ihm buchstäblich ins Herz geschrieben wäre“. An anderer Stelle sagt er zum gleichen Thema „der Wille Gottes (ist) ursprünglich in unser Herz geschrieben" ${ }^{\text {“109. }}$.

\subsection{Wojtyla}

Die reale Relation zur Wahrheit ${ }^{110}$ ist für Wojtyla von großer Bedeutung, weil das Gewissen nicht immer objektiv das Gute erkennt. Erst die richtige Auffassung der Wahrheit ermöglicht den Subjekten das richtige Urteil über die Wirklichkeit des erkannten Gutes. Es genügt deshalb nicht lediglich über das bewusste Handeln zu sprechen, sondern es ist nötig gemäß der Wahrheit zu handeln, damit die Tat gut zu bewerten ist. Tadeusz Styczeń entfaltete diesen Gedanken folgendermaßen: „Im Gewissen, also in meinem Urteil: Ich soll..., geht es letztendlich um die Verpflichtung, den anderen zu affirmieren

${ }^{106}$ A. Winter, „Es ist ein Gott denn es ist ein categ. Imperativ“, S. 90.

${ }^{107}$ Ebenda, S. 91. „Gott also und dein künftiges Leben sind zwei von der Verbindlichkeit, die uns reine Vernunft auferlegt, nach Prinzipien eben derselben Vernunft nicht zu trennende Voraussetzungen“.

${ }^{108}$ N. Fischer, Die Gottesfrage in der Philosophie Immanuels Kants, Herder 2010, S. 91.

${ }^{109}$ Den Heiden ist nach dem Römerbrief des Apostel Paulus die Forderung des Gesetzes ins Herz geschrieben.

${ }^{110}$ „Christus lehrt uns eine ganz besondere Sensibilität gegenüber dem Menschen, seiner Würde als menschlicher Person, dem menschlichen Leben, dem Geist und Körper des Menschen. Diese Sensibilität bezeugt gerade die Kenntnis jener ,Wahrheit, die uns frei macht“ (vgl. Joh 3, 32). Es ist dem Menschen nicht gestattet, diese Wahrheit vor sich selbst zu verbergen“. K. Wojtyla, Von der Königswürde des Menschen, Stuttgart 1980, S. 264. 
nach dem Maß seiner und meiner Würde “111. In meinem Handeln bin ich der Autor der nicht nur äußerlichen Wirkung, sondern wirke auch auf mich selbst in der Dimension des Guten und Bösen, deshalb wird eine vollbrachte Tätigkeit im Zusammenhang mit der Analyse der Selbstbestimmung zum Kriterium des ethischen Urteilens. Es geht um die ethische und personale Qualität meines Handelns. Das Sollen und Pflichtbewusstsein, das ein Subjekt in seiner Freiheit/Sittlichkeit als Entscheidungsträger (Person) offenbart, zeigt sich in ,jene(m) Moment, das das Handeln einer Person eindeutig von allem unterscheidet, was in ihr lediglich geschieht ${ }^{\star 112}$. Eine Tat ist bewusstes Handeln ${ }^{113}$. Gerade durch die eigenen, authentischen Entscheidungen: ,ich kann, aber ich muss nicht" zeigt sich der Mensch in seiner Würde, die gleichzeitig als Gabe und Aufgabe und Herausforderung der Freiheit zu verstehen ist. Der Mensch kann sich auch gegen die erkannte Wahrheit entscheiden, aber gerade aus dieser Erfahrung ergibt sich das Faktum der Schuld, der Sünde, des moralisch Bösen, was den menschlichen Willen in die innere Relation zur Wahrheit stellt. Für Wojtyla ist die Frage der recht verstandenen Freiheit fundamental verbunden mit der Erkenntnis der Wahrheit und der daraus folgenden Tat. Über diese Erfahrung der Pflicht als Gegenstand des freien Willens schreibt Wojtyla folgendermaßen: „Die Würde des Menschen anerkennen heißt, ihn selbst höher zu stellen als alles, was in der konkreten Welt von ihm geschaffen wird. Alle Werke des Menschen, die in Zivilisationen und Kulturen hervorgebracht wurden und in ihnen entstanden sind, stellen nur einen Bereich von Mitteln dar, deren sich der Mensch bei seinem Streben nach dem ihm gemäßen Ziel bedient. Der Mensch lebt weder für die Technik, die Zivilisation, nicht einmal für die Kultur; er lebt mit ihrer Hilfe, dabei stets seine eigene Bestimmung bewahrend. Diese Bestimmung ist eng mit der Wahrheit verknüpft, denn der Mensch ist ein vernünftiges Wesen und ein Gut, das Gegenstand seines freien Willens ist" $" 114$.

${ }^{111} \mathrm{~W}$ sumieniu, czyli moim sądzie: powinienem, [...] chodzi ostatecznie o powinność afirmowania drugiego na miarę godności tego drugiego i miarę godności afirmującego". T. Styczeń, Ja w świetle swego sqadu: powinienem, „Roczniki Filozoficzne” 28 (1980) Z. 2, S. 90-111.

${ }^{112} \mathrm{~K}$. Wojtyła, Osoba i czyn oraz inne studia antropologiczne, S. 426.

${ }^{113}$ Wojtyla untersucht die Schlüsselfrage: Wie lässt sich aus meinen Taten, aus meinem Handeln verstehen wer ich bin? „Człowiek poniekąd staje się osobą poprzez podejmowane wolne decyzje - i w zależności od jakości tychże czynów, ich wartości mierzonych w kategoriach dobra lub zła, tworzy siebie”. K. Wojtyła, Ocena możliwości zbudowania etyki chrześcijańskiej przy założeniach systemu Maxa Schelera, Lublin 1959, S. 31.

${ }^{114}$ K. Wojtyła/Johannes Paul II., Von der Königswürde des Menschen, Stuttgart 1980, S. 45. 
The Person and the Challenges
Volume 3 (2013) Number 1

Nach Kardinal Wojtyla kann erst in einer Öffnung der menschlichen Praxis auf Gott hin der Mensch den vollen Sinn seiner Transzendenz finden ${ }^{115}$. Das Pflichtbewusstsein und Sollen, das ein Subjekt in seiner Entscheidung, in seiner Selbstbestimmung und Handlung entdeckt, weist implizit auf die innere Freiheit hin ${ }^{116}$.

\section{Der kategorische Imperativ als Hinweis auf Gott}

\subsection{Kant}

Für Kant ist der kategorische Imperativ eine Form der Offenbarung Gottes: „,in der moralisch-praktischen Vernunft und dem kategorischen Imperativ

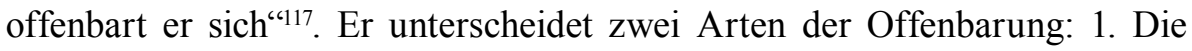
natürliche innere Offenbarung, die mit dem moralischen Gesetz verbunden ist. 2. Die äußere Offenbarung, die die erste voraussetzt, um überhaupt Gott erkennen zu können. In dieser Hinsicht stimmt Kant mit Thomas von Aquin überein. Auch die römische theologische internationale Kommission hat im Jahr 2009 bestätigt, dass man Gutes tun und Böses meiden soll sei natürlicherweise und direkt bekannt ${ }^{118}$. Die praktische Vernunft verlangt von jedem Menschen das Gute zu tun und das Böse zu meiden. Diese ursprüngliche Nötigung ist mehr als ein Interesse, sie drängt sich den Menschen „Kraft seiner moralischen Anlage unwiderstehlich“ auf ${ }^{119}$. Der Mensch ist dabei frei diese unwiderstehliche Kraft als Motor und Motiv seiner Handlung anzuerkennen oder abzulehnen, sonst müssten wir von einem Determinismus sprechen. Es geht Kant lediglich bei dem Begriff „unwiderstehlich“ um die Absicht, bei aller Autonomie des Menschen die Tatsache zu betonen, dass der Mensch diese Stimme nicht zurücknehmen kann. Kant verteidigt einerseits

${ }^{115}$ Die Transzendenz der Person offenbart eine falsche Auffassung des Menschen (anthropologischer Fehler) aller materialistischen Interpretationen.

${ }^{116}$ K. Wojtyła, Person und Tat, Herder 1981, S. 120-209.

${ }^{117}$ I. Kant, AA 21,92.

${ }^{118}$ Commissione Teologica Internazionale: Alla ricerca di un'etica universale: Nuovo sguardo sulla legge naturale, 2.2.: L'esperienza morale: „Bisogna fare il bene”. Vgl. Winter, „Es ist ein Gott denn es ist ein categ. Imperativ", S. 95.

${ }^{119}$ I. Kant, $R G V$ B $33=$ AA 6,36. „Der Mensch ist dagegen frei, das Sittengesetz nicht als Bestimmungsgrund seines Handelns in seine Maxime aufzunehmen. Zurücknehmen kann er es allerdings nicht mehr (bei aller Autonomie“. A. Winter, „Es ist ein Gott denn es ist ein categ. Imperativ", S. 95. 
die Autonomie des Willens, andererseits zeigt er auf die passive Seite der praktischen Vernunft, die die Stimme des Gewissens, unabhängig davon ob sie ihm folgt oder nicht, wahrnimmt.

Das Bewusstsein des kategorischen Imperativs, eine unbedingte Pflicht für jeden Menschen, der sich seiner Vernunft bedient, ist wegen ihrer verbindenden Kraft, implizit ein Hinweis auf Gott. Der moralische Gottesbeweis wird durch die Perspektive Kants vertieft. An dieser Stelle müssen wir mit Winter die Interpretation Giovanni B. Salas ablehnen. Der Jesuit, wie viele vor ihm, unterstellt Kant eine absolute Autonomie des Menschen zu lehren, sowie Inkonsequenz in seiner Argumentation, die aber nicht nachzuweisen ist. Im Gegenteil, auch wenn Kant seine Ideen nicht präzise genug formuliert hat, und dadurch den Weg $\mathrm{zu}$ verschiedenen Interpretationen eröffnet hat, lässt sich leicht feststellen, dass manche Interpreten Kant missverstanden haben. In der Natur des menschlichen Geistes liegt, laut Kant, die Quelle des moralischen Gefühls, das den Menschen ermöglicht zwischen Gut und Böse zu unterscheiden ${ }^{120}$. Ohne den Urheber der Welt wären das moralische Gesetz und seine Zweckmäßigkeit gar nicht zu begreifen. Kant beschreibt den Menschen als Bürger zweier Welten. Einerseits durch Freiheit und praktische Vernunft sind wir aktiv zur Autokreation befähigt worden, zugleich aber Untertanen des Reiches der moralischen Ordnung. Der Mensch ist also, laut Kant, kein völlig unabhängiges Wesen, deshalb müssen wir dieses Oberhaupt „nicht bloß als Intelligenz und gesetzgebend für die Natur, sondern auch als gesetzgebendes Oberhaupt in einem moralischen Reiche der Zwecke denken“"121. In seinen Vorlesungen über Moralphilosophie sprach Kant über die Autonomie des Menschen. Die moralische Pflicht ist für den Menschen verbindlich, nicht nur aufgrund bloßer Vernünftigkeit des Menschen. Sie nötigt den Willen aufgrund ihrer Verbindlichkeit. Der Urheber der Verbindlichkeit

\footnotetext{
${ }^{120}$ Selbstverständlich geht es nicht nur um die grobe Unterscheidung, sondern um mehr differenzierte, einzelne moralische Unterscheidungen. An dieser Stelle können wir aus theologischer Sicht an Paulus Worte erinnern, die von den Forderungen des Gesetzes sprechen, welche allen Menschen ins Herz geschrieben wurden (Röm 2,15).

${ }^{121}$ „In Beziehung auf das höchste unter seiner Herrschaft allein mögliche Gut, nämlich die Existenz vernünftiger Wesen unter moralischen Gesetzen, werden wir uns dieses Urwesen als allwissend denken: damit selbst das Innerste der Gesinnungen (welches den eigentlichen moralischen Wert der Handlungen vernünftiger Weltwesen ausmacht) ihm nicht verborgen sei; als allmächtig: damit er die ganze Natur diesem höchsten Zwecke angemessen machen könne; als allgütig, und zugleich gerecht: weil diese beiden Eigenschaften (vereinigt, die Weisheit) die Bedingungen der Kausalität einer obersten Ursache der Welt als höchsten Guts, unter moralischen Gesetzen, ausmachen“, I. Kant, Kritik der Urteilskraft 86. KDB: Immanuel Kant: Werke, S. 299. Vgl. Kant-W Bd. 10, S. 405-406.
} 
kann dabei nicht dieselbe Person, die verpflichtet ist sein, laut Kant. „Sonst lässt sich nicht denken, dass ich dazu verbunden bin, ehe ich nicht anerkannt habe, dass ich gegen den göttlichen Willen eine Verbindlichkeit habe ${ }^{\text {“122 }}$. Diese Verbindlichkeit, die jeder Mensch in seinem Bewusstsein entdecken kann, führt zur Annahme Gottes. In der Metaphysik der Sitten spricht Kant von einer „Pflicht aus einer übersinnlichen Legislation“, der als dominus der moralischen Weltwesen gedacht wird. Ohne diese Voraussetzung (a priori) eines moralischen, vernünftigen und vollkommenen Wesens, kann der Mensch „,keine Kraft haben den Willen zu bewegen“123. In seinem Nachlasswerk schreibt Kant: „es ist ein Gott. Den es ist eine Macht, die aber auch ein Verbindlichkeit für das Ganze

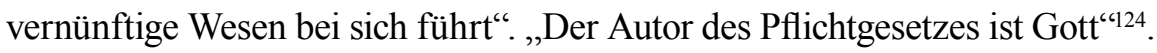

\subsection{Wojtyla}

Ohne verpflichtenden Charakter der moralischen Normen, die wir in unserem Gewissen ablesen können, verliert der Mensch die Orientierung seiner moralischen Handlungen. Oft spielen verschiedene Handlungsbedingungen im Leben eine nicht zu unterschätzende Rolle. „Aber sie sind allemal eingebettet in die Gewissheit: Ich kann - aber ich muss nicht. Damit offenbart sich in der innersten Innerlichkeit des Ich eben diesem Ich ein äußeres Unbedingtes - eine fremde Stimme, die sich nicht mit dem Hinweis auf äußere Bedingungen kleinreden lässt, und die der Mensch, auch wenn sie von außen kommend zu sprechen scheint, doch zugleich als sein eigenes Innerstes erfährt. Paulus hat diese Erfahrung in ein schönes Bild gekleidet, wenn er im Brief an die Römer $(2,15)$ schreibt: Sie ist uns ins Herz geschrieben.“125

Spaemann spricht in diesem Zusammenhang über den Menschen folgendermaßen: ,[...] diese Spur Gottes, die wir selbst sind, existiert nicht, ohne dass wir es wollen, wenn auch - Gott sei Dank - Gott vollkommen unabhängig davon existiert, ob wir ihn erkennen, von ihm wissen oder ihm danken. Nur wir selbst sind es, die sich durchstreichen können. Der Begriff der Gottebenbildlichkeit des Menschen, der oft nur als eine erbauliche Metapher benutzt wird, gewinnt heute eine ungeahnt genaue Bedeutung. Gottebenbildlichkeit, das heißt: Wahrheitsfähigkeit. Wobei die Liebe nichts

\footnotetext{
${ }^{122}$ I. Kant, AA 27,529.

${ }^{123}$ I. Kant, AA 18,519.

${ }^{124}$ I. Kant, AA 21,113.

${ }^{125}$ Ch. Böhr, Metaphysik nach der Postmoderne, Die Tagespost (28.08.2012), Nr. 103, S. 9.
} 
anderes ist als die getane Wahrheit. Liebe kann man ja übersetzen in: Wirklich werden des Anderen für mich“"126.

Wojtyla schreibt in seinem Hauptwerk Person und Tat weniger explizit über Gott. Er konzentriert sich in seinen Untersuchungen auf die Frage: Was ist der Mensch? Die anthropologische phänomenologische Beschreibung des Menschseins führt ihn zur Feststellung der dem Menschen eigenen personalen Würde, die sich in verantwortlicher Teilnahme an der Liebe (Tat) offenbart. Bei der Lektüre von Person und Tat gewinnt man den Eindruck, der Krakauer Philosoph bemühe sich um ausschließlich philosophische Argumente in der Beschreibung der handelnden Person, die sich durch ihre Taten offenbart. Der kategorische Imperativ erscheint deutlich bei der Beschreibung der menschlichen Verantwortung ${ }^{127}$ und Liebe, verstanden als Beziehung zwischen zwei Personen (Mann und Frau). Die personale Norm (eine originelle Modifikation des kategorischen Imperativs) definiert nach Wojtyla das moralische Sollen der würdigen Hingabe zwischen zwei sich gegenseitig schenkenden Personen. „Wenn in deinem Verhalten eine Person Objekt deines Handelns ist, vergiss niemals, dass du sie nicht bloß als Mittel, als Werkzeug behandeln darfst, sondern sei dir bewusst, dass sie ihr eigenes Ziel hat oder wenigstens haben

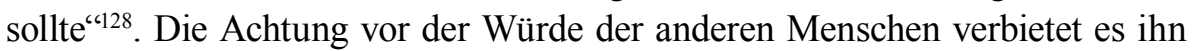
$\mathrm{zu}$ instrumentalisieren und als Sache zu benutzen. Die gegenwärtige Krise der Kultur hängt auch damit zusammen, dass das Menschenbild oft verkürzt, materialistisch, ökonomisiert (homo öconomicus) und utilitaristisch dargestellt wird. Wie Robert Spaemann in seinem Buch „Personen“ überzeugend argumentiert, ist es Zeit die Personenwürde jedes Menschen als unantastbar von Anfang bis zum Ende des Menschenlebens zu definieren. Der zentrale Begriff der Menschenrechte - Person - scheint heutzutage großen Angriffen ausgesetzt zu werden. Wie Spaemann feststellt, ist es in den letzten Jahren zu dramatischen Veränderungen in unserer Kultur gekommen. „Nicht als Menschen sollen Menschen Rechte haben sondern nur, soweit sie Personen sind. Nicht alle Menschen aber und nicht Menschen in jedem Stadium ihres Lebens und in jeder Verfassung ihres Bewusstseins sind, so wird uns gesagt,

\footnotetext{
${ }^{126}$ R. Spaemann, Rationalität und Gottesglaube, http://www.kath-info.de/gottesglaube.html

${ }^{127}$ „Verantwortung ist die besondere Eigentümlichkeit einer Tat, in der sich die Fähigkeit der Person zu handeln zeigt und zugleich verwirklicht". K. Wojtyła, Person und Tat, Freiburg /Br. 1981, S. 34.
}

${ }^{128}$ K. Wojtyła, Liebe und Verantwortung, S. 25. 
Personen“"129. Auch Jörg Splett spricht in seinem Aufsatz „Anthropologie aus christlicher Erfahrung" über die gefährliche Tendenz der heutigen Kultur: „Höchst bedrohlich ist das heute herrschende Personenverständnis (im Rückgriff von J. Locke) vom aktuellen Bewusstsein her statt vom Sein, mit der Sequenz, sowohl Ungeborenen wie Komapatienten das Personsein abzusprechen, bis hin zu der Position D. Parfits, für den sogar Schlafende keine Personen sind“"130.

Ohne Transzendenz-Perspektive, ohne Gott verliert der Mensch seine Würde ${ }^{131}$ und die Achtung vor sich selbst, es droht ihm die Versuchung den anderen $\mathrm{zu}$ instrumentalisieren und nur utilitaristisch auszunutzen. Die personale Norm Wojtylas, ähnlich wie der kategorische Imperativ Kants, bilden damit einen wirksamen Schutzwall dem Ansturm immer mehr freizügiger Freiheit als Willkür verstanden, zu widerstehen. Die gegenwärtigen Tendenzen, die keine moralischen Normen anerkennen wollen und sich lediglich nach den egoistischen Maßstäben orientieren, sind eine Folge der Relativierung der Wahrheit und dem Verlust der Rationalität. Die Erfüllung des sittlichen Sollens, die reale Urheberschaft der Person setzt die Erfahrung des Sollens-Anspruchs voraus. Diese Erfahrung scheint heute in Gefahr zu sein. „Es geht heute um das weltweite Ringen um den Menschen, genauer um die Grundvorstellungen vom Sein und Sollen des Menschen ${ }^{\text {“132. }}$

\section{Fazit}

Der kantische kategorische Imperativ findet seine Widerspiegelung in der Philosophie Karol Wojtylas nicht nur deshalb, weil der Krakauer Philosoph seine personale Norm im Anschluss an Kant formuliert hat, sondern auch in der Übereinstimmung der, in der Einführung gestellten, wesentlichen Fragen,

\footnotetext{
${ }^{129}$ R. Spaemann, Personen. Versuche über den Unterschied zwischen ,etwas “ und ,jemand“, Klett-Cotta, Stuttgart 1996, S. 10.

${ }^{130}$ J. Splett, Anthropologie aus christlicher Erfahrung, S. 53.

${ }^{131}$ „Die Würde der menschlichen Person findet ihre volle Bestätigung in der Tatsache der Offenbarung selbst. Diese Tatsache nämlich bedeutet: die Anknüpfung einer Beziehung zwischen Gott und dem Menschen. Dem Menschen, den Er zu seinem Bilde schuf, überträgt Gott seine Gedanken und Vorhaben. Und mehr noch, Gott nimmt Menschengestalt an, kraft der Offenbarung nimmt Er teil am Drama des menschlichen Schicksals [...]“. K. Wojtyła/Johannes Paul II., Vor der Königswürde des Menschen, Stuttgart 1980, S. 46.

${ }^{132}$ N. Fischer, Sein und Sinn der menschlichen Freiheit in der Philosophie Kants, in: Ch. Böttigheimer, N. Fischer, M. Gerwing (Hg.), Sein und Sollen des Menschen, Münster 2009, S. 1.
} 
die er ähnlich wie der deutsche Philosoph, wie oben gezeigt, beantwortet. Selbstverständlich gibt Wojtyla eine eigene Interpretation des Geheimnisses des Menschseins. Er benutzt dabei eine eher poetische, auch mystische, thomistische und phänomenologische Sprache, um die Wahrheit der menschlichen Erfahrung auszudrücken. In Anknüpfung an den Kantischen Gedanken: so gewiss wie der funkelnde „bestirnte Himmel über mir“, so ist auch die innere Stimme (moralisches Recht) in mir, die uns Gott offenbart ${ }^{133}$, beschreibt Karol Wojtyla den Menschen. Ähnlich wie der Königsberger Denker sieht er den Menschen als eine Person, die durch ihre Taten nicht nur die eigene Freiheit und Würde offenbart, sondern im moralischen Gesetz auf Gott hinweist. Beide Autoren stimmen im Wesentlichen überein. Für beide Denker hängt die Antwort auf die Schlüsselfrage nach dem Menschen von der Beantwortung der Fragen ab: Ist der Mensch frei? Gibt es Gott (ein ewiges Leben)? Was soll der Mensch tun? Der kategorische Imperativ, als innere Stimme (moralisches Recht) in jeder Person verhilft die Dynamik des Menschseins, einerseits auf das sich wandelnde Subjekt hin, andererseits auf Gott hin zu verstehen. Zusammenfassend können wir die Philosophie des Autors von „Person und Tat", die in wesentlichen Punkten mit Kants praktischer Philosophie übereinstimmt, folgendermaßen darstellen: ich bin eine Person mit unantastbarer Würde, die durch die Entscheidungsfreiheit zu verantwortlichen, menschenwürdigen Taten fähig ist und in der Begegnung mit dem anderen Du (Person, Gott) an der Liebe teilnehmen kann und sie verwirklichen soll. Der Autor von Person und Tat sagt dazu: „Aus pastoraler Sicht habe ich in Liebe und Verantwortung den Begriff der personalistischen Norm formuliert. Diese Norm ist der Versuch, das Gebot der Liebe in die Sprache der philosophischen Ethik zu übersetzen. Der Mensch ist ein Wesen, dessen einzig angemessene Dimension die Liebe ist. Wir werden einem Individuum gerecht, wenn wir es lieben: Dies gilt für Gott wie für die Menschen. Die Liebe zu einer bestimmten Person schließt aus, daß man diese als Gebrauchsgegenstand behandelt. Diese Norm findet sich bereits in der Ethik Kants und stellt den Inhalt des sogenannten zweiten Imperativs dar“134. Übereinstimmend mit der Lehre des II. Vatikanischen Konzils können wir den Kategorischen Imperativ (Kant)/personalistische Norm (Wojtyla) als

${ }^{133}$ I. Kant, KpV A 288f. Vgl. N. Fischer, Sein und Sinn der menschlichen Freiheit in der Philosophie Kants, S. 25.

${ }^{134}$ Johannes Paul II, Die Schwelle der Hoffnung überschreiten, Hamburg 1994, S. $225 \mathrm{ff}$. 
The Person and the Challenges
Volume 3 (2013) Number 1

Grundlage der Menschenwürde und praktischen Hinweis - als Offenbarung Gottes interpretieren, weil ,der Mensch auf Erden die einzige von Gott um ihrer selbst willen gewollte Kreatur ist, [die] sich selbst nur durch die aufrichtige Hingabe selbst vollkommen finden kann" ${ }^{\text {"135. }}$.

\section{Bibliography}

Aristoteles, Nikomachische Ethik, Berlin 2006.

Aquin Thomas von, Auswahl der Summe der Theologie, Kröner 1985.

Aquin Thomas von, http://www.corpusthomisticum.org/iopera.html (19.10.12).

Aquin Thomas von, Summa contra gentiles, Wissenschaftliche Buchgesellschaft 1974.

Benatar D., Better never to have been: the harm of coming into existence, Oxford 2006.

Benedikt XVI., Caritas in Veritate, Vatican 2009.

Benedikt XVI., In Gott ist unsere Zukunft, Leipzig 2011.

Benedikt XVI., Wir müssen anders leben! Damit die Schöpfung überleben kann, Herder 2012.

Benedikt XVI., Gott und die Welt. Glauben und Leben in unserer Zeit. Ein Gespräch mit Peter Seewald. Stuttgart u.a.2000, Neuausgabe 2005.

Białoszewski M., Atak zombie, „Fronda“ 53 (2009).

Breuer C., Die Ökologie des Menschen, in: J. Kreiml, Neue Ansage des Glaubens, Regensburg 2012, S. 114-149.

Böttigheimer Ch., Fischer N., Gerwing M. (Hg.), Sein und Sollen des Menschen, Münster 2009.

Davies B., The Thought of Thomas Aquinas, Oxford 1992.

Dreier H., Grundgesetz, 2. Aufl., Tübingen 2004.

Dulles A., Jan Pawel II wobec tajemnicy osoby ludzkiej, „Ethos” 19 (2006) Nr. 4 (76), S. 39-53.

Fischer N., Müssen Katholiken weiterhin Furcht vor Kant haben? Kants Philosophie als sancilla theologiae`, Katholische Universtät Eichstätt-Ingolstadt, Kastner 2005.

Fischer N., Kants Rechtfertigung von Metaphysik und Religion. Die kritische Philosophie als sancilla theologiaer?, in: N. Fischer (Hg.), Kant und der Katholizismus, Herder 2005, S. 19-32.

Fischer N. (Hg.), Kants Grundlegung einer reinen Metaphysik, Meiner Verlag Hamburg 2010.

Fischer N., Sein und Sinn der menschlichen Freiheit in der Philosophie Kants, in: Böttigheimer Ch., Fischer N., Gerwing (Hg.), Sein und Sollen des Menschen, Münster 2009.

Fischer N., Vom Rang und vom Sinn der Gottesfrage in der Philosophie Kants, Die Gottesfrage in der Philosophie Immanuel Kants, Herder 2010.

${ }^{135}$ Gaudium et spes, Nr. 24. Vgl. Johannes Paul II, Die Schwelle der Hoffnung überschreiten, Hamburg 1994, S. 226. 
Fischer N., Der menschliche Wille als scausa primar. Augustins Radikalisierung der Freiheitsproblematik., Vom Rang und vom Sinn der Gottesfrage in der Philosophie Kants, in: Böttigheimer Ch., Fischer N., Gerwing M. (Hg.), Sein und Sollen des Menschen, Münster 2009.

Fischer N., Die Gottesfrage in der Philosophie Immanuel Kants, Herder 2010.

Forschner M., Kants Gottesbild in der »Religionsschrift«, in: N. Fischer, Die Gottesfrage in der Philosophie Immanuels Kants, Herder 2010.

Frossard A., Nie lękajcie się. Rozmowy z Janem Pawłem, Kraków 1983.

Galarowicz J., Człowiek jest osobą, Kraków 1994.

Gudium et spes, Herders Theologischer Kommentar zum Zweiten Vatikanischen Konzil (HthK Vat.II): Apostolicam actuositatem; Dignitatis humanae; Ad gentes; Presbyterorum ordinis; Gaudium et spes: BD 4, Herder 2005.

http://www.vatican.va/archive/hist_councils/ii_vatican_council/documents/vat-ii_const 19651207_gaudium-et-spes_gè.html.(19.10.12).

Hołub G., Being a Person and acting as a Person, "Forum Philosophicum" 13 (2008).

Johannes Paul II., Redemptor hominis, Rom 1979.

Johannes Paul II., Die Schwelle der Hoffnung überschreiten, Hamburg 1994.

Kant I., Kritik der Urteilskraft, Könemann Verlag 1995.

Kant I., Kritik der reinen Vernunft, Köln 2011.

Kant I., Kritik der praktischen Vernunft, Köln 2011.

Kasper W., Barmherzigkeit. Grundbegriff des Evangeliums - Schlüssel christlichen Lebens, Herder 2012.

Kupczak J., Destined for Liberty. The Human Person in the Philosophy of Karol Wojtyła/ John Paul II., Washington D.C. 2000.

Kasper W., Barmherzigkeit. Grundbegriff des Evangeliums - Schlüssel christlichen Lebens, Herder 2012.

Kühn M., Kant. Eine Biografie, München 2003.

Lehmann K., Es ist Zeit an Gott zu denken, Herder 2000.

Meadows D., Die Grenzen des Wachstums, Stuttgart 1972; The Limits to Growth. Universe Books, 1972.

Müller G.L., Einführung zu Benedikt XVI, Spe Salvi, Augsburg 2008.

Nissing H.-G. (Hg.), Einleitung und Übersetzung, in: K. Wojtyla, Wer ist der Mensch? Skizzen zur Anthropologie, München 2011, S. I-LXV.

Ockenfels W., Was kommt nach dem Kapitalismus?, Augsburg 2011.

Ong A., John Paul It's Philosophy of the Acting Person: A Personalistic Approach to Life, Edwin Mellen Press Ltd, 2008.

Rehder S., Bioethiker werben für Kindsmord, Die Tagespost, Nr. 28 (6.03.2012), S. 2.

Rymkiewicz K., Von der Grundlegung der christlichen Ethik zur Grundlegung der philosophischen Anthropologie. Eine kritische Untersuchung zum Personbegriff bei Karol Wojtyla, Berlin 2002.

Spaemann R., Personen. Versuche über den Unterschied zwischen ,etwas “ und ,,jemand“. Klett-Cotta, Stuttgart 1996.

Schwartländer J., Der Mensch ist Person, Mainz 1968. 
Schweidler W., Das Unantastbare: Beiträge zur Philosophie der Menschenrechte, Lit. Verlag 2001. Ders. Über Menschenwürde. Der Ursprung der Person und die Kultur des Lebens, Wiesbaden 2012.

Schweidler W., Über Menschenwürde. Der Ursprung der Person und die Kultur des Lebens, Wiesbaden 2012.

Spaemann R., Communio 32 (Winter 2005), Nr. 2, S. 618-636.

Spaemann R., Rationalität und Gottesglaube, http://www.kath-info.de/gottesglaube.html. (19.10.12).

Spaemann R., Über Gott und die Welt, Klett-Cotta, Stuttgart 2012.

Spaemann R., Personen. Versuche über den Unterschied zwischen „etwas “ und ,jemand". Klett-Cotta, Stuttgart 1996.

Splett J., Anthropologie aus christlicher Erfahrung, in: H.G. Nissing (Hg.), S. Zekorn, Staunend vor dem Menschen. Das Denken Papst Johannes Pauls II., Kevelaer 2001.

Stagliano A., Ecce homo. La perona, Lidea di cultura e la "questione antropologica" in Papa Wojtyla, Siena 2008.

Stala J., Die Transzendenz als bestimmendes Merkmal der Person in der Anthropologie und Pädagogik Johanes Paul II, ,The Person and the Challenges“ 2 (2012), S. 61-75.

Weigel G., Der Papst der Freiheit, Paderborn 2011.

Winter A., Der andere Kant. Zur philosophischen Theologie Immanuel Kants, HildesheimZürich-New York 2000.

Wojtyła K., Person und Tat, Herder 1981.

Wojtyła K., Osoba i czyn oraz inne studia antropologiczne, Towarzystwo Naukowe KUL, Lublin 2000.

Wojtyła K., A. Szostek, T. Styczeń, Der Streit um den Menschen. Personaler Anspruch des Sittlichen, Kevelaer 1979.

Wojtyła K., Person and Community: Selected Essays, Peter Lang, New York 1993.

Wojtyła K., Liebe und Verantwortung, München 1981; Love and Responsibility, Ignatius Press, San Francisco 1993.

Wojtyła K., Świętego Jana od Krzyża nauka o wierze, Tow. Nauk. KUL Lublin 2000.

Wojtyła K., Der Glaube bei Johannes vom Kreuz, Wien 1998.

Wojtyła K., Zagadnienie wiary w dziełach św. Jana od Krzyża, „Ateneum Kapłańskie” 42 (1950), S. 24-42.

Waleszczuk Z., Globalizacja solidarności, Wrocław 2007.

Williams G.H., The Mind of John Paul II. Origins of his thought and Action, New Zork 1981.

Winter A., Der andere Kant. Zur philosophischen Theologie Immanuel Kants, HildesheimZürich-New York 2000.

Winter A., „Es ist ein Gott denn es ist ein categ. Imperativ“. Versteckte Ansätze zur Gottesfrage in der Kritik der praktischen Vernunft, in: N. Fischer, Die Gottesfrage in der Philosophie Immanuels Kants, Herder 2010.

Winter A., Kann man Kants Philosophie >christlich nennen?, in: N. Fischer (Hg.), Kant und der Katholizismus, Herder 2005, S. 33-57. 